\title{
Systemic risk and bank size
}

Article

Accepted Version

Creative Commons: Attribution-Noncommercial-No Derivative Works 4.0

Varotto, S. and Zhao, L. (2018) Systemic risk and bank size. Journal of International Money and Finance, 82. pp. 45-70. ISSN 0261-5606 doi:

https://doi.org/10.1016/j.jimonfin.2017.12.002 Available at https://centaur.reading.ac.uk/74559/

It is advisable to refer to the publisher's version if you intend to cite from the work. See Guidance on citing.

To link to this article DOI: http://dx.doi.org/10.1016/j.jimonfin.2017.12.002

Publisher: Elsevier

All outputs in CentAUR are protected by Intellectual Property Rights law, including copyright law. Copyright and IPR is retained by the creators or other copyright holders. Terms and conditions for use of this material are defined in the End User Agreement.

www.reading.ac.uk/centaur

\section{CentAUR}

Central Archive at the University of Reading

Reading's research outputs online 


\title{
Systemic Risk and Bank Size
}

\author{
Simone Varotto ${ }^{\mathrm{a}}$ \\ ICMA Centre \\ Henley Business School \\ University of Reading
}

\author{
Lei Zhao
}

Finance Department

ESCP Europe

\begin{abstract}
In this paper we analyse firm level systemic risk for US and European banks from 2004 to 2012. We observe that common systemic risk indicators are primarily driven by firm size which implies an overriding concern for "too-big-to-fail" institutions. However, smaller banks may still pose considerable systemic threats, as exemplified by the Northern Rock debacle in 2007. By introducing a simple standardisation, we obtain new risk measures that often prove to be superior predictors of financial distress during the 2007-2009 subprime crisis. We conclude that the new measures could be a valuable addition to the existing indicators employed in Basel III to identify systemically important banks.
\end{abstract}

JEL Classification: G01, G21, G28

Keywords: Systemic Risk, Financial Crisis, Bank Regulation, Too-Big-To-Fail

\footnotetext{
${ }^{a}$ ICMA Centre, Henley Business School, University of Reading. Address: Whiteknights Park, Reading, RG6 6UR, UK. Tel +44 (0)118378 6655, email: s.varotto@icmacentre.ac.uk.

${ }^{b}$ Finance Department, ESCP Europe, Paris Campus, 79, avenue de la République, 75543 Paris Cedex 11, France, T+33149232773, email: 1zhao@escpeurope.eu.
} 


\section{Introduction}

As a result of the sub-prime crisis of 2007-2009 and the sovereign debt crisis that followed, systemic risk in the finance industry has become a hot topic in academic and policy circles. This is because of the substantial damage a financial crisis may cause to the real economy (see, for example, Caprio and Klingebiel, 1996 and Hoggarth, Reis and Saporta 2002) and the fact that financial institutions do not internalize the costs of such negative externality. As a consequence, addressing systemic risk is at the heart of new financial regulation such as the

Dodd-Frank Act in the US and the new Basel III agreement. A capital surcharge is required by Basel III on domestic and global systemically important banks (BCBS, 2012 and 2013). On the other hand, the Dodd-Frank Act explicitly emphasizes the need to provide enhanced regulation of firms and sectors that pose systemic risk (Richardson, 2011). A Pigouvian tax has also been proposed to force systemically important financial institutions (SIFIs) to internalise the costs of crises and thus reduce their severity (see Morris and Shin, 2008 and Acharya et al., 2011, Acharya et al 2016, Bosma, 2016). However, the first step towards any solution to the problem of systemic instability is the derivation of accurate systemic risk indicators and the correct identification of SIFIs.

A variety of systemic risk measures has been proposed since the start of the sub-prime crisis. Bisias et al (2012) provide a comprehensive summary, and emphasise that there is no single "pressure gauge" that can fully detect crises. Indeed, Hansen (2013) warns that model misspecification can be a serious challenge when trying to devise systemic risk measures. A possible solution is suggested by Giglio Kelly and Pruitt (2016) who exploit the information content of a broad selection of systemic risk measures by combining them into indexes. Among the individual measures in the literature $\triangle \operatorname{CoVaR}$ is one of the most popular. Put forward by Adrian and Brunnermeier (2016), it uses quantile regressions to measure the increased Valueat-Risk $(\mathrm{VaR})$ of the financial system when a specific financial firm is in distress. Girardi and 
Ergun (2013) generalize the original $\triangle \operatorname{CoVaR}$ by extending the definition of financial distress to include more severe events. Further refinements have been proposed by López-Espinosa et al (2015) and Sedunov (2016). While $\Delta$ CoVaR focuses on system losses conditional on a bank's distress, most other indicators take the opposite view and determine the systemic risk posed by an institution as the institution's loss conditional on system distress. The idea is that the more a bank is susceptible to market upheavals, the more it can contribute to the severity of a crisis. This second set of measures can be based on reduced form or structural model approaches. SRISK as developed by Brownlees and Engle (2017) and Acharya, Engle and Richardson (2012) belongs to the former type. Lehar (2005)'s indicator is an example of the latter. It exploits the capital structure of a bank in a Merton-type framework to assess its default risk. This information is then embedded into a systemic risk indicator expressed as a regulator's risk exposure to the bank's default.

The main contribution of this paper is the introduction of standardised systemic risk measures. Although large banks are commonly considered of systemic importance and firm size is typically an important driver of systemic risk measures (see, for instance, De Jonghe, 2010, Hovakimian, Kane and Laeven, 2012, Huang, Zhou and Zhu, 2012,Vallascas and Keasey, 2012, Zhang et al 2015, Laeven et al, 2016, and Sedunov, 2016), there is growing evidence that size may not be a persistent determinant of systemic risk in past crises (Weiß, Bostandzic and Neumann, 2014), nor be a prominent contagion factor among large international banks (LopezEspinosa et al, 2012 and 2013). We propose a standardisation of systemic risk indicators that enables us to control for the overshadowing effect of firm size and bring forth other factors that contribute to the systemic importance of an institution, namely interconnectedness and default risk. Specifically, interconnectedness has attracted a lot of interest in recent years and has led to the development of models of interbank lending and contagion through networks (Poledna 
et al, 2015, Kanno, 2015, Hautsch et al, 2015, and Betz at al, 2016). ${ }^{2}$ Danielsson et al (2016)

question the reliability of current systemic risk measures on the basis that they entail substantial estimation risk. Our standardized indicators could help to address this concern in that, even though they are straightforward extensions of existing models, yet they appear to improve systemic risk forecasting.

Our second contribution is a new measure of systemic risk for individual banks. We propose a hybrid indicator that extends the structural model proposed by Lehar (2005) to embed a time varying default barrier. This is then combined with the conditional capital shortfall proposed by Brownlees and Engle (2017) and Acharya, Engle and Richardson (2012) to gauge bank distress in a crisis. Through a structural model, one can explicitly define a crisis as the joint default of a group of institutions. In Brownlees and Engle (2017), a crisis event is instead defined as a $40 \%$ decline in the 6 -month cumulative return of a stock market index. However, not all large stock price corrections may trigger collective defaults. ${ }^{3}$ For instance, the burst of the internet bubble in the early 2000s led to a stock market contraction of about $50 \%$ from peak to trough (for S\&P500 as well as FTSE100) but without the systemic implications seen during the recent Great Recession. In this sense, the crisis condition used by Brownlees and Engle (2017) is more "systematic", while the structural model approach is more "systemic". Our findings suggest that the systemic risk rankings produced by our new (non-standardised) hybrid indicator are consistent with the designation of systemic importance given to US and European banks by the Financial Stability Board (FSB), and with rankings obtained by Brownlees and

\footnotetext{
2 Taking into account feedback loops, a network based structural model is also adopted by Gauthier, Lehar and Souissi (2012) to examine the impact of macro-prudential capital requirements on systemic risk. Paltalidis et al (2015) use networks to model contagion at the country level and find that sovereign risk is the most important channel that amplifies systemic risk in the Euro area. The nexus between systemic risk and sovereign risk is also confirmed by Pagano and Sedunov (2016) at the country level and by Black et al (2016) with a bank level analysis.

${ }^{3}$ While our definition of a financial crisis is also sensitive to negative stock market returns, a big drop in the market index is in itself not enough to trigger a systemic crisis. In our model, unlike in Brownlees and Engle (2017) the vulnerability of the banking system measured by its effective short term leverage is also important. It is conceivable that banks may not default even after a severe stock market contraction if their leverage is low. On the other hand, a milder erosion of market value might have systemic consequences in a high leverage scenario.
} 
Engle (2017)'s indicator. Such consistency is not unexpected as it is primarily driven by size effects. Moreover, the standardised version of our hybrid indicator appears to be one of the best predictors of bank distress, across all other indicators studied in the paper. Occasionally, it outperforms all the other measures in our out-of-sample tests. Specifically, for US banks, the new standardised measure is the best pre-crisis predictor of the largest contractions in bank stocks during the 2007-2009 crisis. For European banks, it is the best in-crisis predictor of the largest stock price drops during the second phase of the crisis. The unquestionable relevance of size as a core systemic risk factor combined with the importance of non-size factors when predicting bank risk in a crisis lead to the conclusion that standardised and non-standardised measures complement one another and both should be considered by financial researchers and for regulatory purposes.

The rest of the paper is organized as follows. Section 2 describes our methodology. Section 3 introduces the sample and data sources. Section 4 presents our empirical results and Section 5 concludes.

\section{Methodology}

In this Section, we first develop our hybrid systemic risk indicator, $r S Y R$. Then, we discuss our standardisation procedure to control for size effects.

\subsection{A hybrid systemic risk indicator}

In order to measure the systemic risk posed by individual institutions, we define financial distress as the event that occurs when a bank's assets fall below the bank's debt at a future time t. The actual market value of total assets of a financial firm $A_{i, t}$ is not observable in that a bank's portfolio is composed of both traded securities and non-traded assets. As a result, we model equity as contingent claims (a call option) on the bank's assets and back out the asset value 
accordingly. One may argue that this procedure may not be appropriate as the efficiency of stock markets during a crisis has been called into question. If stock prices are not efficient or rational, then the information they convey is poor. Although this may be true, a sharp contraction of a firm's stock price, whether in an efficient or inefficient market, can generate serious disruption for the firm and may have contagion implications for other firms as clearly exemplified by the free fall in stock prices of a number of banks after the Lehman Brother default in 2008. So, whether a stock price is efficient or not, its variation may have systemic repercussions. Further, as maintained by Malkiel (2011), it is unlikely that the no arbitrage hypothesis that underpins market efficiency was violated during the subprime crisis. In other words, although stock prices were not measuring firm value accurately, it is doubtful that investors could rely on other value indicators or information that were systematically more accurate than stock prices. Put another way, when there is thick fog, nobody can see clearly. Indeed, systemic risk indicators based on stock prices and contingent claim analysis are very common both in the literature and among practitioners, especially when analysing crisis periods, as summarized in Bisias et al. (2012) and Blancher et al. (2013). Examples include Lehar (2005), Gray, Merton, and Bodie (2007), the International Monetary Fund (2009), Suh (2012), and Jobst and Gray (2013).

Debt $\mathrm{D}_{\mathrm{i}, \mathrm{t}}$, our "effective" level of short term indebtedness which represents the default trigger for bank $i$, is difficult to determine due to the complexity and opaqueness of a bank's balance sheet, as pointed out, for example, by Crosbie and Bohn (2003). To quantify $\mathrm{D}_{\mathrm{i}, \mathrm{t}}$, we need to take into account short-term debt and part of long-term debt as suggested by Moody's KMV and Vassalou and Xing (2004). ${ }^{4}$ However, instead of choosing a somewhat arbitrary portion of long-term debt to determine the default trigger (it is 50\% in the Moody's KMV

\footnotetext{
${ }^{4}$ Vassalou and Xing (2004) state: "It is important to include long term debt in our calculations for two reasons. First, firms need to service their long-term debt, and these interest payments are part of their short term liabilities. Second, the size of long term debt affects the ability of a firm to roll over its short-term debt, and therefore reduce its risk of default."
} 
model), we assume, similarly to Suh (2012), that the $\mathrm{D}_{\mathrm{i}, \mathrm{t}}$ is a portion of total liabilities $\mathrm{L}_{\mathrm{i}, \mathrm{t}}$, namely $\mathrm{D}_{\mathrm{i}, \mathrm{t}}=\delta_{\mathrm{i}, \mathrm{t}} \mathrm{L}_{\mathrm{i}, \mathrm{t} .}$. Note that, unlike in Suh's paper, $\delta_{\mathrm{i}, \mathrm{t}}$, our percentage “default barrier", is time-varying because we intend to capture the changing market perception of the barrier over time.

Assuming that the asset value of a bank follows a Geometric Brownian Motion (GBM), under the risk-neutral measure, the bank's equity $\mathrm{E}_{\mathrm{i}, \mathrm{t}}$ can be seen as a call option on the bank's assets with a strike price equal to debt with maturity at $\mathrm{T}\left(D_{i, T}\right)$. Following Ronn and Verma (1986) and Lehar (2005), we assume that all debt issued by the bank is insured and hence riskless. It follows that its yield must be the risk-free rate. Then, the present value of debt, that is the discounted value of the strike price in the call option pricing equation $e^{-r_{f}(T-t)} \mathrm{D}_{\mathrm{i}, \mathrm{T}}$, will simply be the debt's current value $D_{i, t}$. So, a bank's stock price can be expressed as:

$E_{i, t}=A_{i, t} N\left(d_{1 t}\right)-D_{i, t} N\left(d_{2 t}\right)$

with

$$
\begin{aligned}
& d_{1 t}=\frac{\ln \left(A_{i, t} / D_{i, t}\right)+\left(\frac{\sigma^{2}}{2}\right) T}{\sigma \sqrt{T}} \\
& d_{2 t=} d_{1 t}-\sigma \sqrt{T}
\end{aligned}
$$

where $\sigma$ is the asset return volatility, $\mathrm{T}$ is assumed to be 1 year, following the convention, and $\mathrm{N}(\cdot)$ is the cumulative standard normal density function.

The assumption that all bank debt was effectively insured during the crisis is supported by the extensive guarantees given (implicitly or explicitly) by governments to bank debt, including non-deposit liabilities, during the sub-prime crisis (Demirguc-Kunt and Huizinga, 2013). To take into account changes in the capital structure of the banks, which may be pronounced during 
crises, we update our estimates of $\mathrm{D}_{\mathrm{i}, \mathrm{t}}=\delta_{\mathrm{i}, \mathrm{t}} \mathrm{L}_{\mathrm{i}, \mathrm{t}}$ on a monthly basis. The value of $\delta_{\mathrm{i}, \mathrm{t}}$, the implied default threshold as perceived by the market, is obtained from monthly maximum likelihood estimations. The value of $\mathrm{L}_{\mathrm{i}, \mathrm{t}}$, though available with quarterly frequency, is updated monthly, through interpolation, to reflect the trend observed in the current quarter as in Anginer, Demirguc-Kunt and Zhu (2014). In this way we incorporate changes in leverage in a timely manner.

We apply the maximum likelihood estimator proposed by Duan (1994) and Duan (2000) to estimate the parameters of interest of (1):

$$
\begin{aligned}
L(E, \mu, \sigma, \delta)= & -\frac{m-1}{2} \ln (2 \pi)-(m-1) \ln (\sigma) \\
& -\sum_{t=2}^{m} \ln \tilde{A}_{t}-\sum_{t=2}^{m} \ln \left(N\left(\tilde{d}_{1 t}\right)\right)-\frac{1}{2 \sigma^{2}} \sum_{t=2}^{m}\left[\ln \left(\frac{\tilde{A}_{t}}{\tilde{A}_{t-1}}\right)-\mu\right]^{2}
\end{aligned}
$$

where $\mathrm{m}$ is the number of observations and $\mu$ is the expected asset return. The estimation of $\mu, \sigma, \delta$ and $A_{t}$ follows an iterative procedure. First, $\sigma$ and $\delta$ are given an initial value. Then, the estimate of $A_{t}\left(\tilde{A}_{t}\right)$ is implied from equation (1). Next, parameters $\mu, \sigma$ and $\delta$ are obtained by maximising the likelihood function in equation (2). Following this, the estimated $\sigma$ and $\delta$ are used as new initial values. Iterations stop when the increase in the value of the likelihood function or the change of parameters is smaller than $1 \mathrm{e}-8$.

For each bank in our sample, the monthly time series of total assets $A_{t}$ and the corresponding parameters of the process $\sigma, \mu$ and $\delta$ are estimated, using a rolling window of the previous twenty-four months, as in Lehar (2005).

\footnotetext{
${ }^{5}$ We thank Jin-Chuan Duan and Tao Wang for sharing their Matlab code.
} 
After the time series of total assets has been derived, we measure time-varying asset volatilities and correlations through the well-known EWMA model:

$\sigma_{i j, t}=\lambda \sigma_{i j, t-1}+(1-\lambda) \ln \left(\frac{A_{i, t}}{A_{i, t-1}}\right) \ln \left(\frac{A_{j, t}}{A_{j, t-1}}\right)$

where $\sigma_{i j, t}$ is the covariance between asset returns of bank $\mathrm{i}$ and $\mathrm{j}$ at time $\mathrm{t}$. Following the RiskMetrics framework developed by J.P. Morgan, the decay factor $\lambda$ is set equal to 0.94 .

For each month in the sample period, a variance-covariance matrix $\left(\Sigma_{\mathrm{t}}\right)$ can be estimated using Equation (3). The matrix will be employed in Monte Carlo simulations to take into account banks' "interconnectedness" when calculating overall systemic risk in the industry and the systemic risk contribution of individual banks. Following Lehar (2005), we define overall systemic risk as the probability of a crisis event which occurs when the proportion of the assets of distressed banks to the total assets of all banks exceeds a certain threshold $\theta$ (e.g. $\theta=10 \%$ ) over the next six months: ${ }^{6}$

Overall systemic risk $_{t}=$ Prob $[$ Crisis $]$

$$
=\operatorname{Prob}\left[\sum_{i}\left(A_{i, t+1} \mid A_{i, t+1}<\delta_{i, t} L_{i, t+1}\right)>\theta \sum_{i} A_{i, t+1}\right]
$$

where we assume that $L_{i, t+1}=L_{i, t} \cdot{ }^{7}$

We derive the systemic risk contribution of a bank, SYR, as the bank's expected capital shortfall during a crisis:

\footnotetext{
${ }^{6}$ An overall systemic risk index can also be calculated in terms of the number of banks in distress, see Lehar (2005) and Suh (2012).

${ }^{7}$ Here, for simplicity, we assume that the growth rate of liabilities is zero. This does not appear to be a strong assumption in our setup because equation (4) is estimated every month and bank liabilities are updated with that frequency based on trends observed in financial statements at the start and end of the current quarter. So, any changes in leverage would be promptly reflected in our systemic risk measures.
} 
$S Y R_{i, t}=E\left[\left(k A_{i, t+1}-\right.\right.$ Equity $\left._{i, t+1}\right) \mid$ Crisis $]$

where $\mathrm{k}$ is the minimum leverage, measured as an equity-to-asset ratio, which is set in Basel III at $3 \%$ of total assets. ${ }^{8} k A_{i, t+1}$ then represents a non-risk based minimum capital requirement. According to Basel III regulation such a requirement appears to be a necessary complement to risk based capital measures because it is less subject to manipulation by banks and not influenced by inherent problems in regulatory risk weights. ${ }^{9}$

A relative measure of $S Y R_{i, t}$ that takes into account the systemic importance of a bank in relation to the systemic risk in the financial system can be easily calculated as:

$r S Y R_{i, t}=\frac{\operatorname{Max}\left(0, S Y R_{i, t}\right)}{\sum_{i}\left(S Y R_{i, t} \mid S Y R_{i, t}>0\right)}$

In order to compute the above systemic risk variables, at each point in time in the sample period, Monte Carlo simulations are used to generate future scenarios of bank-specific asset values. In each scenario, the multivariate distribution of predicted asset values at a given future horizon (e.g. in 6 months) is obtained by using the Cholesky-decomposition of the variancecovariance matrix $\left(\Sigma_{\mathrm{t}}\right)$ estimated with the EWMA model. So, a scenario $\mathrm{s}$ at time $\mathrm{t}+1$ is generated as:

$A_{i, t+1}^{S}=A_{i, t} \exp \left(\mu_{i, t} T+\operatorname{Chol}\left(\Sigma_{t}\right)^{T} \varepsilon_{t} \sqrt{T}-\frac{1}{2} \sigma_{i}^{2} T\right)$

\footnotetext{
${ }^{8}$ Replacing 3\% with $8 \%$, as in SRISK, does not qualitatively change our results.

${ }^{9}$ For example, the internal rating based approach in Basel II uses risk weights that are based on several assumptions (e.g. single risk factor model, well diversified portfolio, ...) which may not be appropriate for all banks across all portfolios.
} 
where $\operatorname{Chol}\left(\Sigma_{\mathrm{t}}\right)$ is an upper triangular matrix so that $\Sigma_{\mathrm{t}}=\operatorname{Chol}\left(\Sigma_{\mathrm{t}}\right)^{\mathrm{T}} \operatorname{Chol}\left(\Sigma_{\mathrm{t}}\right)$ and $\varepsilon_{\mathrm{t}}$ is a standard normal random variable. We simulate $A_{\mathrm{i}, \mathrm{t}+1}^{\mathrm{s}}$ for 100,000 scenarios simultaneously for all banks, each month in the sample period.

\subsection{Standardisation of systemic risk measures}

In this work in addition to $r S Y R$ we also consider other popular systemic risk indicators to do comparative tests of their predictive power. These other measures are Brownlees and Engle (2017)'s SRISK, Adrian and Brunnermeier (2016)'s $\Delta$ CoVaR and Lehar (2005)'s expected shortfall $(E S)$. As we find that firm size is often a dominant contributing factor in popular systemic risk measures, which can overshadow other factors (e.g. leverage and interconnectedness), we also employ standardized versions of all the above. For all indicators, except $\Delta \operatorname{CoVaR}$, standardisation is achieved by simply dividing the original measure by the bank's total assets. $\triangle \mathrm{CoVaR}$ is not amenable to this type of standardisation as it is expressed in terms of the total loss suffered by the system (when a bank is in distress) rather than the loss suffered by a bank ( $r S Y R$ and SRISK) or the bank level contribution to systemic risk (ES). As the system is normally proxied with the stock index of the banking sector, for $\triangle \mathrm{CoVaR}$ we counteract the effect of bank size by computing the index with equal weights rather than value weights. This way, bank size will effectively be standardised, as all banks will equally influence the index. Definitions of all the systemic measures used in this study are summarised in Appendix 2.

\section{Data}

We conduct our study on US and European banks for the period December 2001 to December 2012. Our sample includes all Euro area countries which joined the Eurozone before 
2002. We add three more countries with large systemically important banks: the United Kingdom, Switzerland and Sweden. We first select all commercial banks and investment banks ${ }^{10}$ active at the end of 2006 and available in Compustat North America (for US banks) and Compustat Global (for European banks). Then, following Laeven, Ratnovski and Tong (2016) (1) we exclude micro-banks, with assets below \$10bn in the US (€10bn in Europe), as they are unlikely to pose any systemic threat ${ }^{11}$; and (2) we classify the remaining institutions as small/large if they have assets below/above $\$ 50 \mathrm{bn}$ as of December 2006. Dead banks are retained to address survivorship bias. Next, we apply similar filters, as in Zhang et al. (2015) to ensure that for each bank we have 1) sufficient data to estimate all the eight measures of systemic risk included in this study, over a period of two consecutive years; and 2) more than $80 \%$ of non-zero stock returns over the sample period to avoid thin trading biases. Our final sample consists of 83 US banks and 55 European banks. A list of selected banks is reported in Appendix 1. We collect daily stock prices, number of shares outstanding and quarterly balance sheet data from Compustat North America and Compustat Global.

As of December 2006, our US sample represents approximately $95 \%$ of the total assets of all listed banks in the US which are were available in Compustat North America and had an asset value over 5 million US dollars. Similarly, the European banks covered in our sample represent approximately $99 \%$ of the total assets of all listed banks (with an asset value over 5 million US dollars) in the 12 European countries studied in the paper. Despite the broad coverage, our methodology based on stock price information implies that our sample is limited to listed banks. This means that our work does not extend to state-owned banks and banks organised as cooperatives. ${ }^{12}$ These types may be systemically important and will need to be

\footnotetext{
${ }^{10}$ Global Industry Classification Standard (GICS) codes 4010 and 402030.

11 This threshold is commonly used by the Federal Reserve to identify community banks. See https://www.federalreserve.gov/supervisionreg/topics/community_banking.htm.

12 When compared with the banks included in the 2011 stress tests conducted by the European Banking Authority, our sample provides a good representation of important banks in Europe, especially in Belgium, France,
} 
studied with a different approach. Given the extensive coverage of our study, it is unlikely that excluded banks could materially affect our aggregate systemic risk indicators. Although excluded institutions may have a limited impact on systemic risk rankings of individual banks, there is no reason to believe that they would meaningfully alter the cross-sectional or time series properties of our bank-specific systemic risk measures and the findings of our panel analyses.

\section{Empirical findings}

In this Section, we present our analysis of non-standardised (NS) and standardised (S) systemic risk measures in the US and Europe. We start by comparing the systemic risk rankings produced by these measures. Next, we investigate the role of bank size and other balance sheet information as their determinants. Finally, we test the ability of our battery of measures to predict "realised" systemic risk during the recession period.

To set the scene, we first apply the methodology explained in Section 2.1 to measure the magnitude of overall systemic risk in the banking sector. We assume that a systemic event occurs when the proportion of the assets of distressed banks to the total assets of all banks exceeds a threshold $\theta$ within a predetermined time horizon $\tau$. This represents a scenario when normal banking intermediation is severely disrupted and credit supply is reduced to the extent that the real economy is adversely affected. In line with the previous literature (Lehar, 2005 and Suh, 2012), we choose $\theta=10 \%$ and $\tau=0.5$ years. ${ }^{13}$ So a plausible banking sector-wide systemic risk measure is the probability of having such a systemic event given by equation (4). Figure 1 shows the time series of overall systemic risk from December 2003 until December 2012 for both the US and the European banking systems. It is clear that the period with the

\footnotetext{
Ireland, Italy, Sweden and the UK. However, we are unable to cover a large number of unlisted banks in Germany and Spain, even though the largest institutions in these countries are included in our study.

${ }_{13}$ As a robustness check, we derive overall and bank specific systemic risk measures with $\theta$ equal to $5 \%$ and $20 \%$, instead of the $10 \%$ used for our reported results. We do not find significant changes in our findings.
} 
highest probability of a systemic event occurred during the sub-prime crisis of 2007-2009, in both regions. As one would expect, systemic risk increases sharply around the time of critical events, such as the Bear Stearns bailout (March 2008), the Lehman Brothers failure (September 2008) and at the time of increased concerns for a Greek default (Summer 2011).

\subsection{Systemic risk rankings}

Often, institutions that are too-big-to-fail are also considered to be systemically important and vice versa. However, as evidenced by the Norther Rock debacle, smaller institutions can also pose systemic threats. And large institutions that have low risk and are well capitalised may not necessarily be systemic. In other words, size, though an important systemic risk factor may not be the only or the dominant one.

In addition to $r S Y R$ we extend our analysis by considering other well-known indicators and by deriving their standardised counterparts. To exemplify the differences/similarities among various systemic risk indicators, in Appendix 3 we report a snapshot of their rankings of US banks (Panel A) and European banks (Panel B) as of December 2011. We also show the (unranked) list of SIFIs released by the Financial Stability Board (FSB) in November 2011.14 It is interesting to note that for the US (European) banks the ranking based on our indicator $r S Y R$ shares 17 (19) out of 20 top risky banks with Brownlees and Engle (2017)'s indicator SRISK. The consistency of our results with SRISK is further confirmed with their high correlation during the sample period as shown in Table $1(0.52$ for US banks and 0.90 for European banks). More importantly, the 8 (14) systemically important US (European) banks identified by the FSB are captured within the top $12(18)$ in the ranking of $r S Y R$. At the same time, Appendix 3 also highlights the multifaceted nature of systemic risk as revealed by ranking

\footnotetext{
14 The Financial Stability Board (FSB) is an international body that monitors and makes recommendations about the global financial system. It was established after the G-20 London summit in April 2009 as a successor to the Financial Stability Forum.
} 
differences across measures. Specifically, in contrast to the similarity between $r S Y R$ and SRISK, $\triangle$ CoVaR and ES only share 6 and 11 banks respectively of the top 20 identified by $r S Y R$ in their top 20 lists for the US sample. Similar results are obtained for the European sample. Another interesting observation from Appendix 3 is that standardization makes a difference. For instance, of the top 20 institutions according to $r S Y R$, only 9 (13) enter the top 20 ranking after standardisation for the US (European) sample.

The above findings are corroborated by our rank correlation analysis conducted on quarterly systemic risk rankings over our full sample period (December 2003 - December 2012) as well as the pre-crisis and crisis periods. For each quarter $t$, we compute pair-wise rank correlations for the indicators of interest and then average them over time. Panel A of Table 1 reports the results for the US and Europe over the full sample period. Figure 2 summarises the above information by showing, for each indicator in the NS and S groups, the average rank correlation between the indicator and the others within the same group. To control for the effect of the larger proportion of smaller banks that may create noisy rankings in the US sample relative to the European sample (the proportion of banks with total assets below $\$ 50 \mathrm{bn}$ is $63 \%$ and $18 \%$ respectively in the two regions) in Figure 2 we also report the results obtained from a subsample restricted to the top 30 institutions by asset size in each region. We find that overall, there is substantially positive correlation within NS and S measures, with S measures being less correlated. Controlling for sample size does not appear to alter the outcome. This suggests a reassuring degree of convergence in the assessment of systemic risk. But there are also noticeable differences, as highlighted, for NS measures, by previous literature (Giglio, Kelly and Pruitt 2016, Danielsson et al. 2016, and Zhang et al. 2015). For instance, we observe that $\triangle C o V a R$ has a markedly lower correlation with other NS measures, which is consistent with the low average correlation between SRISK and $\triangle$ CoVaR documented in Benoit et al. (2014). This is to be expected as $\Delta \mathrm{CoVaR}$ represents the risk of the financial system conditional on a 
specific institution being in distress. By contrast, the other NS measures studied in the paper take a different perspective and portray the risk of an institution conditional on a shock to the financial system. In a crisis, the behaviour of banks and their index becomes more synchronised which implies that $\Delta$ CoVaR does not vary as much across banks as for other measures. This makes it more likely to produce discordant rankings. Similarly, standardised $\Delta$ CoVaR has a rather low average correlation (negative in the US sample and across regions when looking at the top 30 banks) with other S measures. We also observe that NS measures are always more correlated in Europe than in the US. This may follow as in the European sample there is a markedly higher proportion of very large banks. ${ }^{15}$ This applies to the full regional cohorts and the ones restricted to the top 30 banks. Since NS measures are primarily driven by size, they will then be more likely to produce consistent rankings for a larger section of the European sample. On the other hand, the average rank correlations of $\mathrm{S}$ measures are more similar between the two regions, especially when the top 30 banks are considered. The correlation analysis results are confirmed when we split the sample between pre-crisis and crisis periods (see Figure 3).

To illustrate the role played by bank size in systemic risk rankings we compute average correlations between the eight systemic risk indicators and size. Results are reported in Table 1 Panel A and graphically summarised in Figure 4. The dominant effect of size is rather obvious for $r S Y R, S R I S K$ and $E S$ in the European sample with rank correlations of $99 \%, 89 \%$ and $70 \%$ respectively. In the US, the values are lower due to the prominence of smaller banks in the sample, but still substantial with an average correlation across NS measures of $49 \%$. As one would expect, S measures are considerably less correlated with size, a result which is consistent

\footnotetext{
15 There are only 4 banks with assets above $\$ 1$ tr in the US sample while there are 13 in the European sample. Furthermore, the Herfindahl index in the US and Europe (and its normalised version) is 0.076 and 0.045 (0.063 and 0.027), respectively (see Panel B in Table 1).
} 
across measures. This suggests that standardization may be effective as a way to control for the overshadowing effect of bank size. This in turn may be useful as a means of identifying medium and small banks that can be systemically relevant or larger banks that may not pose substantial or imminent systemic threats. Further, smaller banks may represent a considerable proportion of the local banking industry, which implies that the fragility of a few small banks may cause concerns about the fragility of many others. This is sometimes referred to as the "too-many-tofail" problem (Acharya and Yorulmazer, 2007), which has recently drawn attention and triggered robust counter-systemic measures in Italy. ${ }^{16}$

\subsection{Determinants of systemic risk measures}

To the extent that systemic risk measures can reflect the systemic importance of an institution, it is of interest to investigate their determinants. We draw from a selection of balance sheet indicators to see if systemic risk can be readily inferred from accounting information. Our priors are that systemic risk should be positively related to size (measured as logarithm of total assets), at least for the NS measures, and leverage, which is a common default risk proxy. By contrast, systemic risk should be negatively related to asset growth, as healthy institutions tend to expand. However, as before the subprime crisis many banks were fast expanding in risky markets, we control for the possible negative effect of abnormal high expansion with a quadratic term for growth. Higher equity capital (especially for poorly

\footnotetext{
16 The Financial Times reported that "Atlante, a privately backed $€ 5$ bn fund rushed into existence in April to quell the threat of contagion from struggling lenders, took control of Veneto Banca ( $€ 33 \mathrm{bn}$ in assets as of 2015) ... and Popolare di Vicenza (€40bn in assets), another regional bank, last month." (Financial Times 30 June 2016). “ . . . the woes of Popolare di Vicenza, which is tiny in relation to the $€ 4$ tn Italian banking industry, should be little more than a footnote in the history of European banking... Instead its shortcomings have triggered fears of nationwide contagion and aroused Europe-wide concerns, and this has forced Italian authorities to lean on some of the country's strongest institutions to stump up billions of euros; the fear is that a regional bank has become too entwined with the rest of the Italian financial system to fail. ... a bail-in of an Italian bank [where losses are forced on private investors] may cause a chain reaction ... across the European banking system. ... "We cannot go bust for $€ 2.5 \mathrm{bn}$," says the chief executive of one of Italy's largest banks, one of a dozen bosses who raced to Rome to find the government waiting, cap in hand." Financial Times, April 15, 2016 [emphasis added].
} 
capitalized banks), asset liquidity, profitability and deposit ratios should also be negatively related to systemic risk as they are typically associated with bank resilience (see Brownlees, 2011, Lehar, 2005, Hovakimian, Kane and Laeven, 2012, and Lopez-Espinosa et al, 2013). Specifically, we measure profitability as return on assets (ROA) and liquidity as the sum of available-for-sale and held-to-maturity securities over total assets, as in Landier, Sraer and Thesmar (2016).

Table 2 contains summary statistics of our regression variables (Panel A) and their pairwise correlations (Panel B) for the US and European samples. Following Brunnermeier, Dong and Palia (2012), quarterly fixed-effects are included in our regressions. We are aware that our dependent variables, i.e. our S and NS measures, come from a first-stage estimation, which may introduce measurement error and, as a result, heteroscedasticity. Since we do not obtain detailed information about the possible measurement error, we use White period standard errors to account for heteroscedasticity (as in Weiß, Bostandzic and Neumann, 2014), as well as possible autocorrelation (see Petersen, 2009) in the regression residuals. ${ }^{17}$ Standard errors are clustered at the firm level.

Multivariate regression results are shown in Table 3. Systemic risk measures as the dependent variables are divided into non-standardized and standardized groups. As we observe high kurtosis for $E S$ and $s E S$ due to outliers, in the regressions we replace them with $\ln (1+$ $E S)$ and $\ln (1+s E S * 1,000,000)$ respectively. Despite the distinct designs and emphases of the various NS systemic risk measures, we find that, when statistically significant, results are broadly in line with expectations and are consistent across the four measures in both geographic regions. As one would expect, banks with larger size, higher leverage and lower profitability tend to be more systemically important in the following quarter. The negative and

\footnotetext{
17 The time fixed effect dummies included in our regressions also help to remove the contemporaneous correlation between observations. Unreported robustness tests using alternative standard error specifications confirm that White period standard errors are the most conservative.
} 
counterintuitive coefficient of leverage obtained from the $\triangle \mathrm{CoVaR}$ regression for the US sample (model 3) is the only exception. This should not be of much concern because most of the explanatory power in model 3 comes from the time fixed effects (with an R-squared of 0.872 against a total of 0.880 ), leaving little variation in $\triangle C o V a R$ to be explained by bank characteristics. It is worth noting that in the US, the R-squared of regressions with the size factor alone is rather high for $r S Y R$ and $S R I S K$ ( 0.659 and 0.301 respectively), but rather small for $\Delta \operatorname{CoVaR}(0.02)$, which is consistent with the finding observed in Figure 4 that $\Delta C o V a R$ is the least correlated with size. The significant coefficients of Assets Growth and Assets Growth ${ }^{2}$ in column 4 for US banks and in columns 1 and 4 for European banks confirm our conjecture that higher asset growth helps to reduce a bank's systemic risk contribution. However, banks expanding too fast tend to be more systemically risky (which is captured by the quadratic asset growth term in the regression). Again, $\triangle \mathrm{CoVaR}$ exhibits counterintuitive signs for the growth variables in the US sample.

Turning to S indicators, standardization is meant to "strip away" the size effects, which can be dominant for some traditional systemic risk measures. Results in Table 3 for both regions reassure us that our standardization is effective, but to differing degrees. The size-only Rsquared decreases after standardization for all four NS measures without any exception. Consistent with our previous findings (see Figure 4), the reduction in the explanatory power of size for $r S Y R$ and $S R I S K$ is the most pronounced in both regions. As the size-only R-squared falls to almost zero across all S measures in the US sample, it is not surprising to see that size is mostly insignificant for these indicators. In stark contrast, size remains an important determinant even after standardization for the European sample (see columns 5 through 8 in Panel B). This suggests that a European bank's systemic risk may grow more than proportionally to its size. 
To illustrate the impact of capital regulation on systemic risk measures we have included the tier 1 ratio in our regressions in Table 3 . To account for the possible asymmetric implications on systemic risk of tier 1 ratio for well capitalized and less capitalized (LC) banks (see Lehar, 2005), we also include in our regressions an interaction term Tier 1 ratio $* L C$, where $L C$ is a dummy variable equal to 1 if a bank's tier 1 ratio is less than $10 \%$ (our sample average). It is interesting to note that in both regions and across S and NS measures, there does not appear to be a consistent relationship between the tier 1 capital ratio and our systemic risk measures. This is not surprising. On the one hand, a higher tier 1 ratio should lead to lower systemic risk because better capitalised banks are, all else equal, safer. On the other hand, regulators can exercise discretion to increase minimum capital requirements ${ }^{18}$ when they are concerned about the safety or the systemic risk of a bank. ${ }^{19}$ So, a higher tier 1 ratio may also be related to higher systemic risk. The combination of these opposing relations between tier 1 capital and systemic risk can cause inconsistencies in regression results and the inference that can be made with different measures even within the same geographical region. For instance, in the US sample, when the tier 1 ratio increases, $s R I S K$ decreases for poorly capitalised banks, that is, the (unreported) sum of the coefficient of the interaction term Tier 1 ratio $*$ LC and the coefficient of Tier 1 ratio is negative and significant. But, it increases for highly capitalized banks, i.e. the coefficient of Tier 1 ratio is positive and significant. This suggests that the relation between tier 1 ratio and systemic risk, as detected by this particular measure, depends on the financial soundness of a bank (i.e. whether it is well capitalized). However, when systemic risk is measured by $s \Delta \mathrm{CoVaR}$, it decreases as tier 1 ratio increases, regardless of

\footnotetext{
${ }^{18}$ Basel II, which was in force for most of the observations period, spells out the principles on which bank supervision should be based. Principle 3 states that "Supervisors should expect banks to operate above the minimum regulatory capital ratios and should have the ability to require banks to hold capital in excess of the minimum.” (BCBS 2006, p. 211).

${ }^{19}$ Basel III formally introduced higher capital buffers for large-systemic banks in 2016. The new rules were not in place during the sample period but national regulators and banks may have made adjustments well before the official date when the new rules were introduced.
} 
whether a bank is well capitalized or not. Inconsistencies across different systemic risk measures are also observed in the European sample.

Overall, if we look beyond size effects, we find more significant and expected coefficients across S measures than for NS measures. This confirms the argument that other risk elements can be overshadowed in traditional systemic risk indicators.

\subsection{Predicting realised systemic risk}

In this section we test the ability of NS and S measures to predict the effects of systemic risk during the crisis in terms of individual banks' (1) stock price contractions, (2) default and (3) inclusion in government bailout programmes.

\subsubsection{Stock price contractions}

First, we look at how S and NS measures computed before the subprime crisis (2007Q2) can predict large stock price contractions during the crisis. Specifically, we employ probit models where the dependent variable takes value 1 when a bank's stock price falls more than $80 \%$ or $90 \%$ between $2007 \mathrm{Q} 3$ and $2009 \mathrm{Q} 1 .{ }^{20} \mathrm{We}$ start by employing systemic risk measures in univariate regressions for a direct comparison of their predictive ability. We then add bank size as a further explanatory variable. This is useful as there is no agreement in the literature regarding the importance of size as a systemic risk predictor. As shown in Table 1 and Figure 4, size has high rank correlation with NS measures and should already be reflected in them. But it could add further explanatory power to the regressions because other systemic risk factors in the NS measures (e.g. interconnectedness and default risk factors) may interfere and prevent it from fully expressing its forecasting ability. However as, in some instances, we detect

\footnotetext{
${ }^{20}$ Banks that disappeared before the end of the crisis due to default or delisting are considered to have had a stock price contraction of $100 \%$.
} 
clear signs of multicollinearity, we replace size with its component that is orthogonal to the relevant NS measure. For consistency we do so across all NS measures and throughout our analysis, unless otherwise stated. The results of large stock price contraction forecasts are reported in Table 4. When we look at univariate regressions, we find that, in the US, most S measures are statistically significant for both $80 \%$ and $90 \%$ stock price drops. For NS measures only ES is consistently significant whether or not we control for size. Interestingly, across all specifications, it is always an $\mathrm{S}$ measure, $s S Y R$, that holds the highest explanatory power, as measured by pseudo R-squared. To further gauge predictive power of significant systemic risk measures we also use the percentage of correctly classified distressed banks and the percentage of correct classifications across all banks as in Zhang et al (2015). To identify banks that are correctly classified, we employ, for each relevant regression specification, the ratio between the observed number of distressed banks and the total number of banks as a cut-off point. Then, a distressed bank will be correctly classified if its distress probability obtained through the probit model is above the cut-off point, while a correctly classified non-distress bank will have its distress probability below the cut-off point. Again, $s S Y R$ produces the highest levels of correct classifications for US banks. Specifically, $75 \%$ and $76 \%$ of distressed banks are correctly classified when considering an $80 \%$ and $90 \%$ drop in stock prices, respectively. When we look at the European sample in Panel B, only sSRISK is always significant. Then, both the US and European samples show that $\mathrm{S}$ indicators are better pre-crisis predictors of crisis-related stock price contractions than NS indicators. Interestingly, size does not appear to have predictive power when used alone. But it becomes significant in the US sample when regressed alongside CoVaR and $\mathrm{SCoVaR}$.

One may argue that it is unlikely that a bank's market-based systemic risk measures could predict its stock price decline over the next 7 quarters. Indeed, the market largely did not anticipate the severity of the subprime crisis. Therefore, we have repeated our analysis by using 
systemic measures estimated in 2008Q1 (rather than 2007Q2), that is 2 quarters into the crisis, but well before the peak represented by the Lehman default in September 2008. Then, in Table 5 we report predictions of banks' stock contractions in the following 4 quarters. Considering stock price drops of $80 \%$ and 90\% from 2008Q2 (rather than from 2007Q3 as done in Table 4) implies that in Table 5 we look at harsher bank distress levels. This is because stock prices had already started to fall prior to 2008Q2. Combining this stronger distress level with systemic risk indicators now measured after the wake-up call of the first signs of system instability causes most NS and S measures to become statistically significant in the US market. In most cases, they also improve their forecasting ability, as measured by the pseudo R-squared and correct classification indicators. For price falls of $80 \%$, it is not obvious which type of systemic indicator dominates as the top performing NS and S measures, ES and SSRISK respectively, have a similar R-squared of about $30 \%$, whether we control for size or not. But if we look at the percentage of correctly classified distressed banks, an indicator that is more relevant for regulators and policy makers, S measures dominate with $S S R I S K$ and $s E S$ rightly predicting $88.9 \%$ of the largest bank stock contractions, without size as a control. For the larger drop of $90 \%$, the correct classification of distressed banks for the two standardised measures increases further to $93.3 \%$. Although size, when regressed alone, is statistically significant in the US for both price drops, it is hardly significant when combined with NS systemic risk measures. This is also the case for $\mathrm{S}$ measures, as the size effect may be present after standardisation. For instance, standardised measures can reflect the fact that large banks may be more systemic because they are more interconnected and tend to have higher default risk. ${ }^{21}$ As far as Europe is concerned, Table 5 Panel B shows that the statistical significance of all systemic risk indicators is almost non-existent except for our newly introduced $\mathrm{S}$ measure, $s S Y R{ }^{22}$ Size is

\footnotetext{
${ }^{21}$ With an international sample, Doupos et al 2015 show that larger banks, all else being equal, tend to have lower Z-scores, an indication of higher default risk.

22 The European results are puzzling and may be due to the interplay of more than one factor. First, the subprime crisis may have affected different national markets in Europe at different times. So, stock contractions
} 
not significant when regressed alone and hardly ever significant when used as a control. The overall conclusion from our analysis of stock price contractions in the crisis period is that when systemic risk is assessed shortly after the start of the crisis, top performing $\mathrm{S}$ measures are either similar or more powerful predictors of realised systemic risk in the US. S measures become more dominant as the level of bank distress increases. In contrast, S measures appear to be the only ones that can forecast large stock price contractions in Europe.

\subsubsection{Bank failure}

We now extend our comparison of NS and $\mathrm{S}$ indicators by assessing their predictions of bank failures during the crisis. In our definition of bank failure we include banks that default or are delisted, for instance following a merger. ${ }^{23} \mathrm{We}$ do not include banks that received bailout money, unless they subsequently fail or are delisted. We do this for two reasons: (1) we do a separate analysis of bank bailouts in Section 4.3.3 and, (2) there is strong evidence that being the recipient of a government bailout is not necessarily correlated with the level of distress of the financial institution. In the US, banks that received capital injections as part of the Capital Purchase Programme sponsored by the government were found to have stronger fundamentals than banks that did not participate in the Program (Ng, Vasvari and Moerman, 2011).

Figure 5 shows some preliminary evidence of the relative effectiveness of NS and S indicators as applied to well-known bank debacles during the subprime crisis. We organise

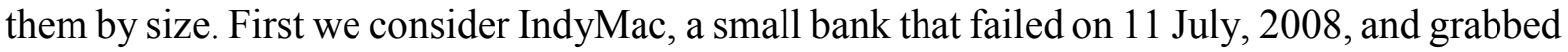
the headlines because, at the time, it was the fourth largest bank default in the United States. We can see that the average rankings of S measures in the quarters before the bank demise are

may not be as synchronised as in the US, which may loosen their connection with systemic measures computed at a specific point in time. Second, European stocks may have partially been affected by news from the US market rather than real systemic events. In other words, the "US-sneezes-and-the-rest-of-the-world-catches-a-cold" scenario may negatively impact on the predictive power of European market-based systemic measures.

${ }^{23}$ Our definition of bank failure is in line with Berger, Imbierowicz and Rauch (2016) and Jin, Kanagaretnam and Lobo (2011). 
consistently lower (denoting higher systemic risk) than the average NS rankings. One may argue that this is not surprising as the relatively small size of the bank did not warrant its inclusion among the most systemic ones. However, the same result is also found for Northern Rock, a medium sized bank whose failure posed an important systemic threat to the UK banking sector; and Washington Mutual, an equivalently high profile default in the US. More surprisingly, we also observe that $\mathrm{S}$ measures consistently indicate higher systemic risk (i.e. lower ranking) for very large banks (assets above \$500bn) in the last available quarter when systemic risk could be measured before their collapse. These are Wachovia in the US and HBOS in the UK. These results suggest that standardization, as formulated in this study, may yield superior early warning indicators of systemic risk for small as well as large institutions.

To check whether the above anecdotal evidence has more general validity we test the performance of NS and S measures when predicting the probability of bank failures, occurred during the sub-prime crisis period (2008Q2 to 2009Q1) . Results are presented in Table 6. In the US, when systemic risk measures are computed before the crisis, neither group of indicators exhibits strong statistical significance (see Panel A). ES is the only measure that is statistically significant at the $10 \%$ level with the expected sign. sCoVaR, when controlling for bank size, is also significant but has a counter-intuitive negative sign, and is accompanied by a highly significant size coefficient. This is the result of a puzzling interaction between the two variables, neither of which is significant in univariate regressions. When size is orthogonalised with respect to $s \operatorname{CoVaR}$, the significance of $s \mathrm{CoVaR}$ disappears.

With systemic risk measures computed at the beginning of the crisis in 2008Q1, the univariate analysis in the US sample reveals that all $\mathrm{S}$ measures are statistically significant at the $5 \%$ or $1 \%$ level. For NS measures only CoVaR and ES are significant. The higher consistency of forecasting ability among $\mathrm{S}$ measures suggests that they are more dependable predictors. Bank size is statistically significant both alone and in all cases when combined with 
NS and S measures, except for ES. This suggests that size effects beyond those reflected in NS and S measures are indeed helpful to predict US bank failures.

In the European sample, the predictive power of systemic risk measures declines relative to the US sample. However, it is only $\mathrm{S}$ measures that have some statistical significance: $S S R I S K$ when computed in the pre-crisis period and $S S Y R$ when computed at the beginning of the crisis. Size does not play any noticeable role.

\subsubsection{Bank bailouts}

Another way to determine the relative accuracy of NS and S measures against realised systemic risk is by testing if they can predict bank bailouts. Following Zhang et al (2015) we have matched our US and European samples against government capital injections from ProPublica for US banks and Petrovic and Tutsch (2009) for European banks. Only 9 US banks that were forced to enter the Capital Purchase Program ${ }^{24}$ are considered to have been bailed-out for the purpose of this analysis, while all those that entered the program voluntarily are left out. Our findings in Table 7 suggest that for the US, NS measures are strongly significant while S measures are not. This suggests that bank size is the primary driver of bailout decisions. Figure 6 shows the strong relationship between bailout amount and bank size. The implication is that the US government paid little attention to the non-size related systemic risk factors and were mostly motivated in its interventions by too-big-to-fail considerations. Indeed, when size is added as a control it is almost invariably highly significant for both NS and S measures. Further, the explanatory power of multivariate regressions for each NS measure and its S counterpart is very similar, again revealing the common influence of size effects. The significance of size when combined with NS measures is plausible because, even though those measures may be

\footnotetext{
24 The Capital Purchase Programme was part of the Troubled Asset Relief Program that was signed into law on October 3, 2008.
} 
mostly driven by size, they are also influenced by other factors. Hence, a pure indicator of size may add explanatory power as it is unhampered by confounding factors. When we run similar regressions but with NS measures orthogonalised with respect to size to eliminate any size effects from them, the measures become, in most cases, insignificant (see Appendix 4). This again lends support to our conclusion about the size motivated actions taken by the US. When we look at Europe in Table 8 Panel B and Appendix 4 Panel B our conclusions are, by and large, confirmed.

\subsection{Policy implications}

While devising a methodology to detect globally systemic important banks (G-SIBs), the Basel Committee, which represents bank regulators and supervisory authorities from 28 jurisdictions, has rejected existing systemic risk measures in the literature. The rationale was that “quantitative models to estimate individual banks' contributions to systemic risk ... are at a very early stage of development and concerns remain about the robustness of the results. The models may not capture all the ways that a bank is systemically important" (BCBS, 2013). Smeasures could provide a bridge towards a more comprehensive assessment of systemic risk. An advantage of these measures is that they are based on existing ones and can be easily computed and interpreted. Their out of sample ability to predict bank distress during recent crises, as documented in this study, indicates that S-measures can provide a fuller picture of systemic risk when combined with NS measures. Further, G-SIBs are currently designated by the Basel Committee on the basis of banks' balance sheet data that do not exploit banks' stock price information. ${ }^{25}$ Then, the refinement of market-based measures would also help to

${ }^{25}$ See Table 1 in BCBS (2013) "Global systemically important banks: updated assessment methodology and the higher loss absorbency requirement" for a list of balance sheet items employed by the Basel Committee to build a bank specific systemic risk score. 
increase regulators' confidence in these indicators. This could broaden and improve the information set currently used to identify G-SIBs.

The Table below illustrates how systemic risk assessment could be improved by combining NS and S measures. For simplicity we identify 4 scenarios produced by possible combinations of high $(\mathrm{H})$ or low $(\mathrm{L})$ systemic risk for the same institution according to different indicators. When both types of measure are consistent with one another the interpretation is straightforward in the sense that systemic risk may $(\mathrm{H}, \mathrm{H})$ or may not $(\mathrm{L}, \mathrm{L})$ be an issue for that institution. However, when the NS and S average rankings are discordant, then further analysis may be needed to arrive at a final conclusion. An indication of high risk from an NS measure may be overshadowed by size effects and hence could be dismissed if the corresponding $\mathrm{S}$ indicator points in the opposition direction. Additional capital may still be required of this institution, as a precautionary measure. By contrast, a low average NS measure may underestimate the risk posed by smaller but risky and highly interconnected entities (with high $\mathrm{S}$ ranking). In this case too, a regulatory capital add-on for systemic risk may be applied.

\section{Systemic risk scenarios}

\begin{tabular}{l|cccc} 
& 1 & 2 & 3 & 4 \\
& & & & \\
\hline Average NS & H & H & L & L \\
\hline Average S & H & L & H & L \\
\hline Systemic risk & H & $?$ & $?$ & L
\end{tabular}

\section{Conclusion}

In this paper we propose ways to improve the assessment of systemic risk in the financial system. As a testing ground we consider the period 2004-2012 that includes both the subprime crisis and the European sovereign debt crisis which have characterised the longest and deepest 
recession since the Great Depression. We put forward a new hybrid systemic risk indicator, $r S Y R$, that combines a well-established structural model of default risk with the concept of conditional capital shortfall. We find that $r S Y R$-based ranking successfully identifies US and European institutions that have been designated as systemically important by the Financial Stability Board.

Further, we propose a new standardisation procedure that enables us to control for the overshadowing effect of bank size. We show that when popular systemic risk indicators (e.g. SRISK, $\triangle$ CoVaR, and ES) as well as $r S Y R$ are standardised, their ability to predict bank distress may markedly improve. We argue that regulators could draw more accurate insights into the multidimensional nature of systemic risk by combining traditional and standardised indicators. More generally, this combination could increase regulators' confidence in marketbased measures which are currently excluded from official scoring models of systemic risk.

Moreover, we observe that the capital injections in the 2011 Capital Purchase Program of the US government and those sponsored by European governments are mainly allocated on the basis of bank size and do not appear to be affected by other factors that may influence systemic risk. This may be a cause for concern, as such factors may have played an important role in relatively smaller bank failures that had major systemic consequences. In contrast, large banks that are well capitalised and have low risk may not necessarily be systemic.

While our research focuses on banks, it could be easily extended to other financial institutions, such as insurance companies, to gain a broader understanding of systemic risk in the financial industry. Moreover, our findings could be used to challenge the conventional association between systemic risk and bank size. As our standardised indicator can help detect systemic risk stemming from smaller banks, it is well suited to complement existing measures to determine how much additional capital or financial penalties (e.g. in the form of a Pigouvian tax) systemically important banks should be charged. 


\section{References}

Acharya, V.V., Engle, R., Richardson, M., 2012. Capital shortfall: A new approach to ranking and regulating systemic risks. The American Economic Review: Papers and Proceedings 102, $59-64$.

Acharya, V.V., Pedersen, L.H., Philippon, T., Richardson, M., 2011. Taxing systemic risk. Chapter 5 in Regulating Wall Street: The Dodd-Frank Act and the new architecture of global finance, Acharya, V.V., Cooley, T., Richardson, M., Walter, I. editors, Wiley Finance.

Acharya, V., Pedersen, L.H., Philippon, T., Richardson, M., 2016. Measuring systemic risk. Review of Financial Studies (forthcoming).

Acharya, V.V., Philippon, T., Richardson, M., Roubini, N., 2009. The Financial Crisis of 2007-2009: Causes and Remedies. Prologue in Restoring financial stability: How to repair a failed system, Acharya, V.V., Richardson, M., editors, Wiley Finance.

Acharya, V. V., Yorulmazer, T., 2007. Too many to fail - an analysis of time-inconsistency in bank closure policies. Bank of England Working Paper no. 319.

Adrian, T., Brunnermeier, M.K., 2016. CoVaR. American Economic Review (forthcoming).

Anginer, D., Demirguc-Kunt, A., Zhu, M., 2014. How does competition affect bank systemic risk? Journal of Financial Intermediation 23, 1-26.

Basel Committee on Banking Supervision (BCBS), 2006. International Convergence of Capital Measurement and Capital Standards, June, BIS.

Basel Committee on Banking Supervision (BCBS), 2011. Global systemically important banks: assessment methodology and the additional loss absorbency requirement. November, BIS.

Basel Committee on Banking Supervision (BCBS), 2012. A framework for dealing with domestic systemically important banks. October, BIS.

Basel Committee on Banking Supervision (BCBS), 2013. Global systemically important banks: updated assessment methodology and the higher loss absorbency requirement, July, BIS 
Benoit, S., Colletaz, G., Hurlin, C., Perignon, C., 2014. A theoretical and empirical comparison of systemic risk measures. HEC Paris Research Paper No. FIN-2014-1030.

Bernanke, B. S., 2010. Remarks on The Squam Lake Report - fixing the financial system Speech at the Squam Lake Conference, BIS Review.

Berger, A.N., Imbierowicz, B., Rauch, C., 2016. The roles of of corporate governance in bank failures during the recent financial crisis. Journal of Money, Credit and Banking 48, 729-770.

Betz, F., Hautsch, N., Peltonen, T. A., Schienle, M., 2016. Systemic risk spillovers in the European banking and sovereign network. Journal of Financial Stability 25, 206-224.

Bisias, D., Flood, M., Lo, A.W., Valavanis, S., 2012. A survey of systemic risk analytics. Working Paper No. 0001, Office of Financial Research, US Department of the Treasury.

Blancher, N., Mitra, S., Morsy, H., Otani, A., Severo, T., Valderrama, L., 2013. Systemic risk monitoring ("SysMo") toolkit—A user guide. Working Paper, IMF.

Black, L., Correa, R., Huang, X., Zhou, H., 2016. The systemic risk of European banks during the financial and sovereign debt crises. Journal of Banking and Finance 63, 107-125

Bosma, J. J., 2016. Dueling policies: Why systemic risk taxation can fail. European Economic Review 87, 132-147

Brownlees, C.T., 2011. On the relation between firm characteristics and volatility dynamics with an application to the 2007-2009 financial crisis. NYU Working Paper.

Brownlees, C., Engle, R., 2017. SRISK: A conditional capital shortfall measure of systemic risk. Review of Financial Studies 30, 48-79.

Brunnermeier, M.K., Dong, G., Palia, D., 2012. Banks’ non-interest income and systemic risk. Working Paper.

Caprio, G., Klingebiel, D., 1996. Bank insolvencies: cross country experience. Policy Research Working Paper No. 1620, World Bank.

Crosbie, P., Bohn, J., 2003. Modeling default risk. Research Report, Moody's KMV. 
Danielsson, J., James, K.R., Valenzuela, M., Zer, I., 2016. Can we prove a bank guilty of creating systemic risk? A minority report. Journal of Money, Credit and Banking 48, 795812.

De Jonghe, O., 2010. Back to the basics in banking? A micro-analysis of banking system stability. Journal of Financial Intermediation 19, 387-417.

Demirguc-Kunt, A., Huizinga, H., 2013. Are banks too big to fail or too big to save? International ecidence from equity prices and CDS spreads. Journal of Banking and Finance $37,875-894$.

Doumpos, M., Gaganis, C., Pasiouras, F., 2015. Central bank independence, financial supervision structure and bank soundness: An empirical analysis around the crisis. Journal of Banking and Finance 61, Supplement 1, S69-S83

Duan, J.-C., 1994. Maximum likelihood estimation using the price data of the derivative contract. Mathematical Finance 4, 155-167.

Duan, J.-C., 2000. Correction: Maximum likelihood estimation using the price data of the derivative contract. Mathematical Finance 10, 461-462.

Gauthier, C., Lehar, A., Souissi, M., 2012. Macroprudential capital requirements and systemic risk. Journal of Financial Intermediation 21, 594-618.

Giglio, S., Kelly, B., Pruitt, S., 2016. Systemic risk and the macroeconomy: an empirical evaluation. Journal of Financial Economics 119, 457-471.

Girardi, G., Tolga Ergun, A. 2013. Systemic risk measurement: Multivariate GARCH estimation of CoVaR. Journal of Banking and Finance 37, 3169-3180.

Gray, D.F., Merton, R.C., Bodie, Z., 2007. New framework for measuring and managing macrofinancial risk and financial stability. NBER Working Paper No. 13607. 
Hansen, L.P., 2013. Challenges in identifying and measuring systemic risk. Forthcoming Chapter 1 in Systemic risk and macro modeling, Brunnermeier, M.K., Krishnamurthy, A. editors, University of Chicago Press.

Hautsch, N., Schaumburg, J., Schienle, M., 2015. Financial Network Systemic Risk Contributions. Review of Finance 19, 685-738.

Hoggarth, G., Reis, R., Saporta, V., 2002. Costs of banking system instability: Some empirical evidence. Journal of Banking and Finance 26, 825-855.

Hovakimian, A., Kane, E., Laeven, L., 2012. Variation in systemic risk at US banks during 1974-2010. NBER Working Paper No. 18043.

Huang, X., Zhou, H., Zhu, H., 2012. Assessing the systemic risk of a heterogeneous portfolio of banks during the recent financial crisis. Journal of Financial Stability 8, 193-205.

International Monetary Fund, 2009. Global financial stability report: Responding to the financial crisis and measuring systemic risks. Working Paper, IMF.

Jin, J.Y., Kanagaretnam, K., Lobo, G.J., 2011. Ability of accounting and audit quality variables to predict bank failure during the financial crisis. Journal of Banking and Finance 35, 28112819.

Jobst, A.A., Gray, D.F., 2013. Systemic contingent claims analysis - Estimating marketimplied systemic risk. Working Paper, IMF.

Kanno, M., 2015. Assessing systemic risk using interbank exposures in the globalbanking system. Journal of Financial Stability 20, 105-130

Laeven, L., Ratnovski, L., Tong, H., 2016. Bank size, capital, and systemic risk: Some international evidence. Journal of Banking and Finance 69, 25-34

Landier, A., Sraer, D., Thesmar, D., 2016. Banks exposure to interest rate risk and the transmission of monetary policy. NBER Working Paper No. 18857. 
Lehar, A., 2005. Measuring systemic risk: a risk management approach. Journal of Banking and Finance 29, 2577-2603.

López-Espinosa, G., Anton, M., Rubia, A., Valderrama, L., 2012. Short-term wholesale funding and systemic risk: A global CoVaR approach. Journal of Banking and Finance 36, $3150-3162$.

López-Espinosa, G., Rubia, A., Valderrama, L., Anton, M., 2013. Good for one, bad for all: Determinants of individual versus systemic risk. Journal of Financial Stability 9, 287-299

López-Espinosa, G., Moreno, A., Rubia, a., Valderrama, L., 2015. Systemic risk and asymmetric responses in the financial industry. Journal of Banking and Finance 58, 471-485 Malkiel, B.G., 2011. The efficient-market hypothesis and the financial crisis. Working Paper. Morris, S., Shin, H.S., 2008. Financial regulation in a system context. Brookings Papers on Economic Activity Fall, 229-274.

Ng, J., Vasvari, F.P., Moerman, R.W., 2011. The Impact of TARP's Capital Purchase Program on the Stock Market Valuation of Participating Banks. Singapore

Management University Working Paper.

Paltalidis, N., Gounopoulos, D., Kizys, R., Koutelidakis, Y., 2015. Transmission channels of systemic risk and contagion in the European financial network. Journal of Banking and Finance 61, S36-S52

Pagano, M. S., Sedunov, J., 2016. A comprehensive approach to measuring the relation between systemic risk exposure and sovereign debt. Journal of Financial Stability 23, 62-78.

Petersen, M.A., 2009. Estimating standard errors in finance panel data sets: Comparing approaches. The Review of Financial Studies 22, 435-480.

Petrovic, A., Tutsch, R., 2009. National rescues measures in response to the current financial crisis. European Central Bank Legal Working Paper Series, July 8. 
Poledna, S., Molina-Borboad, J. L., Martínez-Jaramillo, S., van der Leij, M., Thurner, S., 2015. The multi-layer network nature of systemic risk and its implicationsfor the costs of financial crises. Journal of Financial Stability 20, 70-81

Richardson, M., 2011. The Dodd-Frank Act and systemic risk. Dodd-Frank: one year on, A VoxEU.org eBook.

Ronn, E.I., Verma, A.K., 1986. Pricing risk-adjusted deposit insurance: An option-based model. Journal of Finance 41, 871-895.

Sedunov, J., 2016. What is the systemic risk exposure of financial institutions? Journal of Financial Stability 24, 71-87.

Suh, S., 2012. Measuring systemic risk: A factor-augmented correlated default approach. Journal of Financial Intermediation 21, 341-358.

Vallascas, F. and Keasey, K. 2012 Bank resilience to systemic shocks and the stability of banking systems: Small is beautiful. Journal of International Money and Finance 31, 17451776.

Vassalou, M., Xing, Y., 2004. Default risk in equity returns. Journal of Finance 59, 831-868.

Weiß, G., Bostandzic, D., Neumann, S., 2014. What factors drive systemic risk during international financial crises? Journal of Banking and Finance 41, 78-96.

Zhang, Q., Vallascas, F., Keasey, K., Cai, C. X., 2015. Are Market-Based Measures of Global Systemic Importance of Financial Institutions Useful to Regulators and Supervisors? Journal of Money, Credit and Banking 47, 1403-1442. 


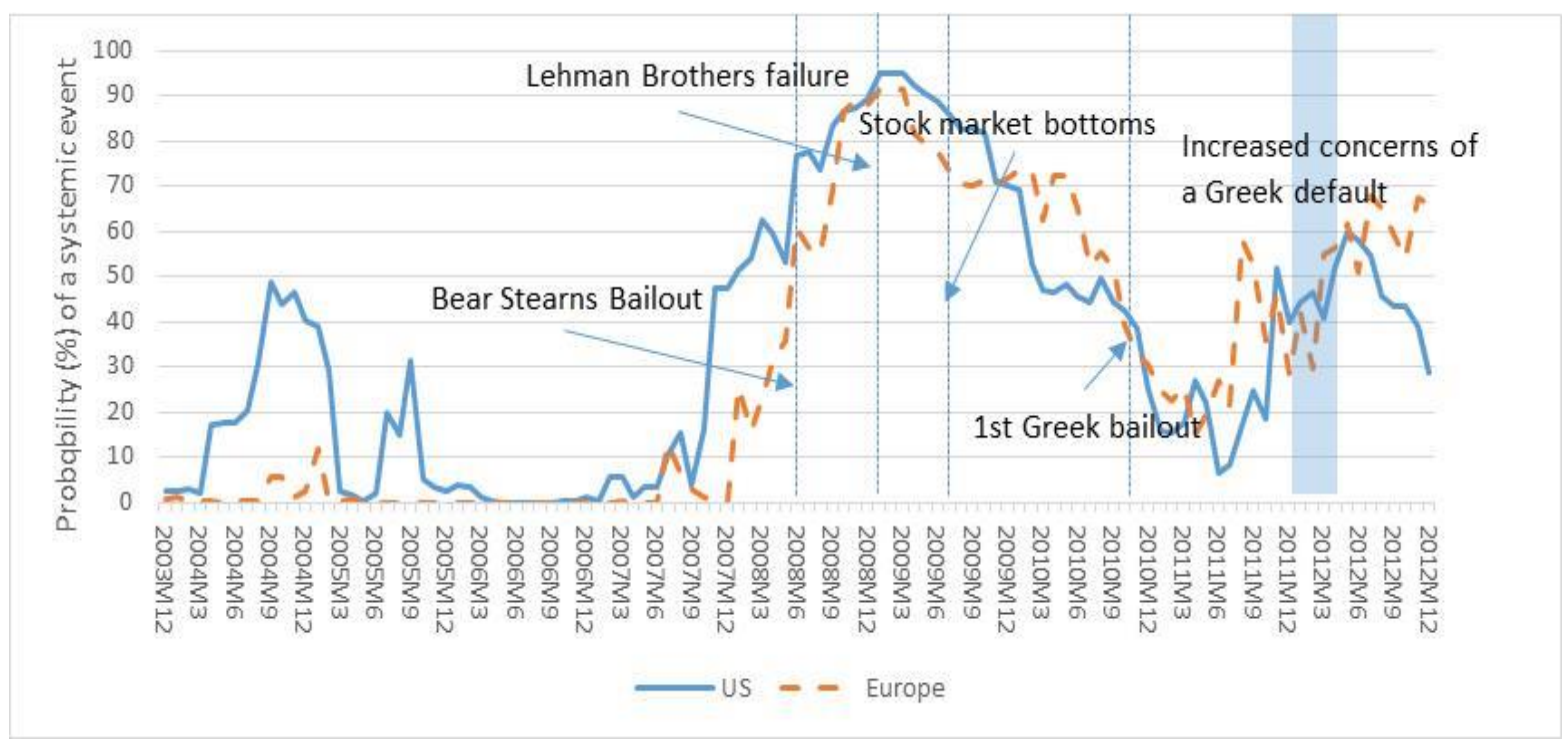

Figure 1. Overall systemic risk in the US and European banking systems. This figure plots the estimated systemic risk in the US and European banking systems. Systemic risk is measured as the probability (\%) that the assets of the banks in distress exceed $10 \%$ of total bank assets over the next six months. 


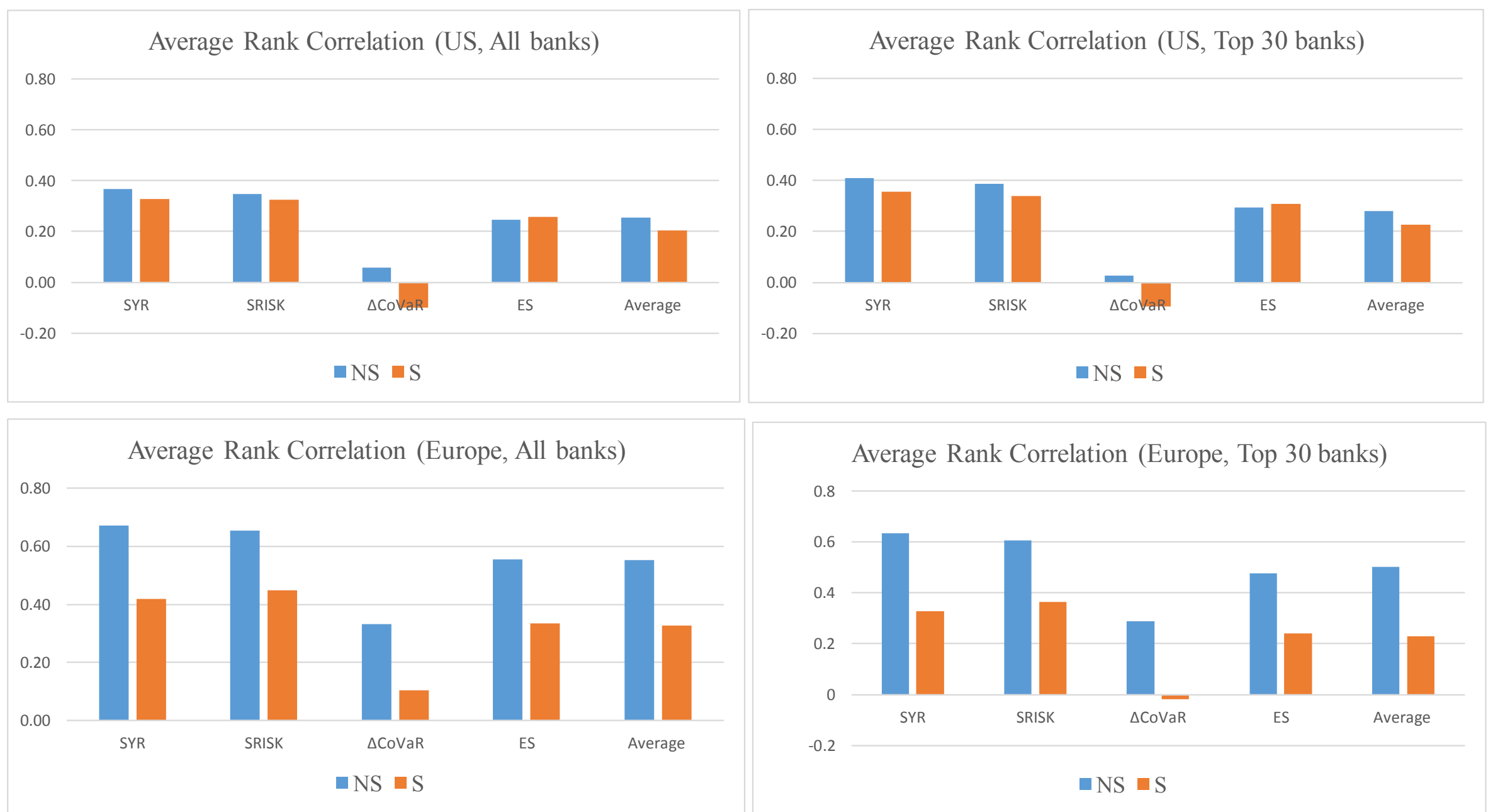

Figure 2. Average rank correlations. This figure reports for each systemic risk indicator in the non-standardised (NS) and standardised (S) groups, the average rank correlation between the indicator and the others within that group over the whole sample period December 2003 December 2012. We also report averages per group. Correlations are calculated for the whole sample and for a subsample consists of only the top 30 institutions by asset size in each region. 


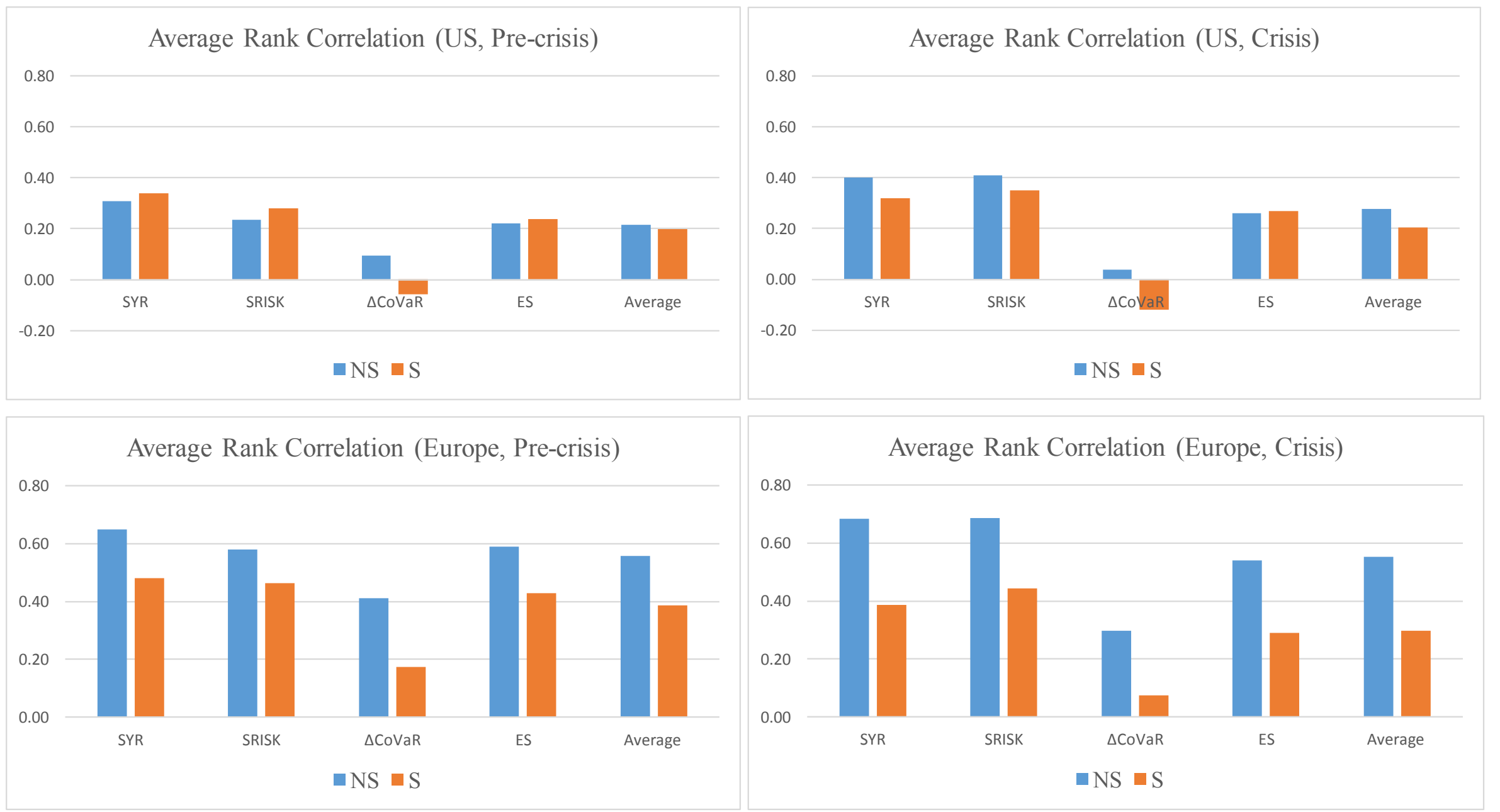

Figure 3. Average rank correlations (pre-crisis vs. crisis). This figure reports for each systemic risk indicator in the non-standardised (NS) and standardised (S) groups, the average rank correlation between the indicator and the others within that group over the pre-crisis period December 2003 - May 2007 and over the crisis period June 2007 - December 2012, respectively. We also report averages per group. 

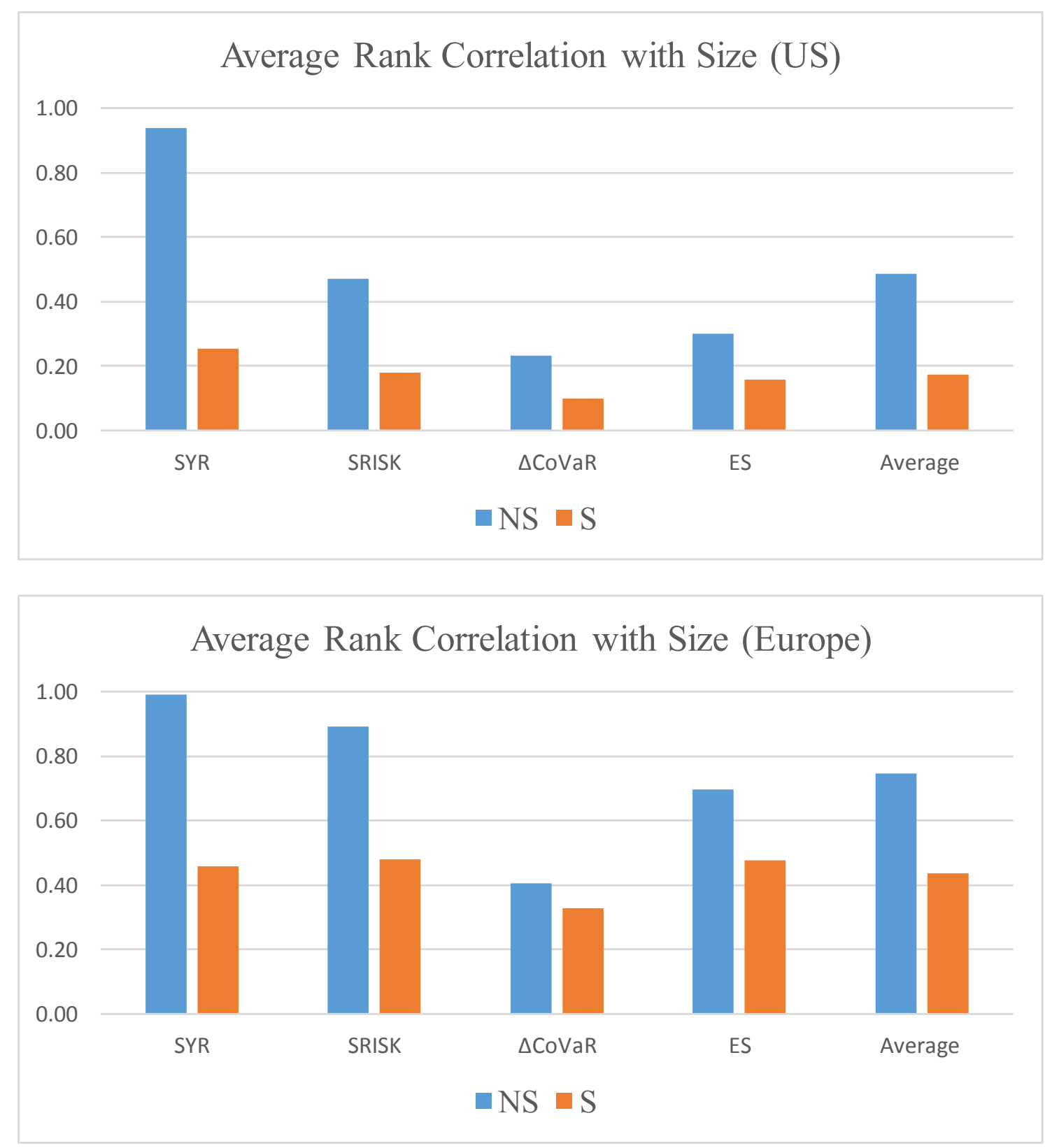

Figure 4. Systemic risk indicators and size. This figure reports for each systemic risk indicator in the non-standardised (NS) and standardised (S) groups, its average rank correlation with bank size over the whole sample period December 2003 - December 2012. We also report averages per group. 
A. Bank with total assets below US\$50 billion



B. Banks with total assets between US\$50 billion and US\$500 billion
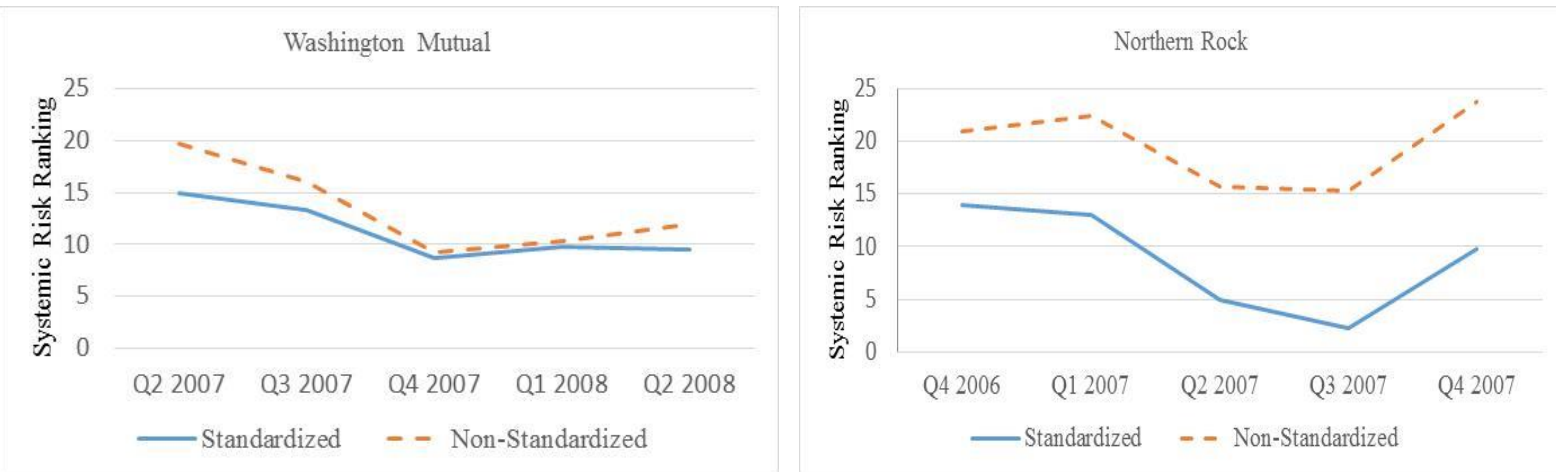

C. Banks with total assets above US\$500 billion
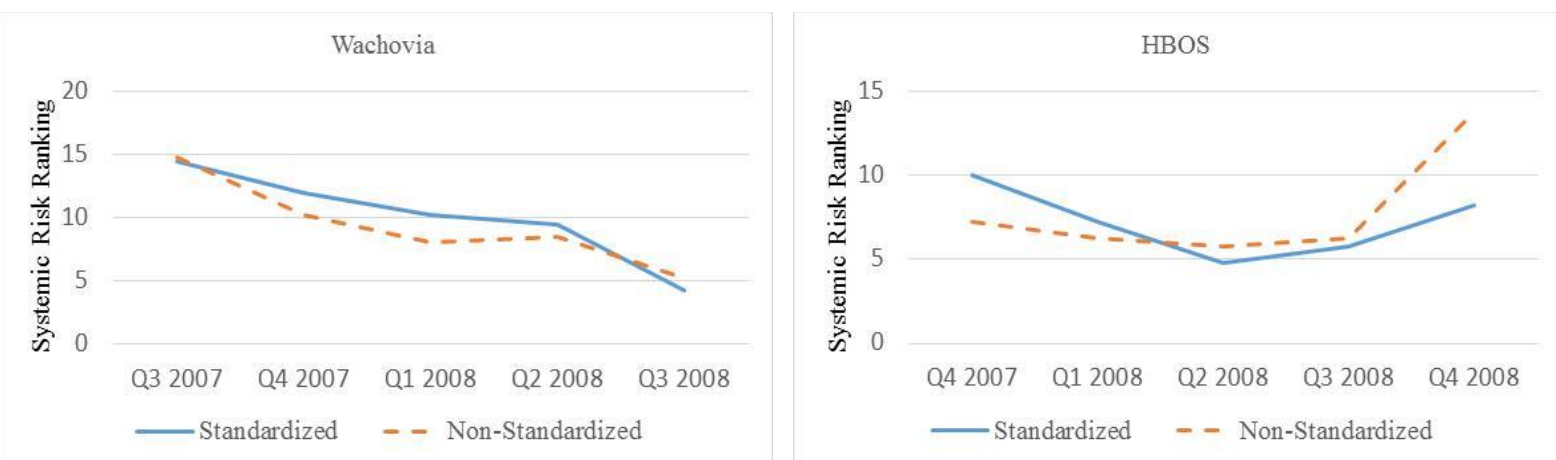

Figure 5. Average systemic risk rankings five quarters before the bailout/demise. This figure shows average systemic risk rankings for IndyMac, Washington Mutual, Northern Rock, Wachovia and HBOS. The averages are calculated across all non-standardized measures (rSYR, SRISK, $\triangle$ CoVaR and ES) and all standardized measures (sSYR, sSRISK, $\mathrm{s} \Delta \mathrm{CoV}$ aR and sES). The rankings for IndyMac, a small bank with total assets less than US\$50 billion in December 2006, are relative to all US banks in our sample. The rankings for Washington Mutual and Wachovia (Northern Rock and HBOS), which are large banks with total assets in excess of US\$50 billion in December 2006, are relative to all large US (European) banks in our sample. For each bank, we report the rankings over the last five available quarters before the failure of the bank. 


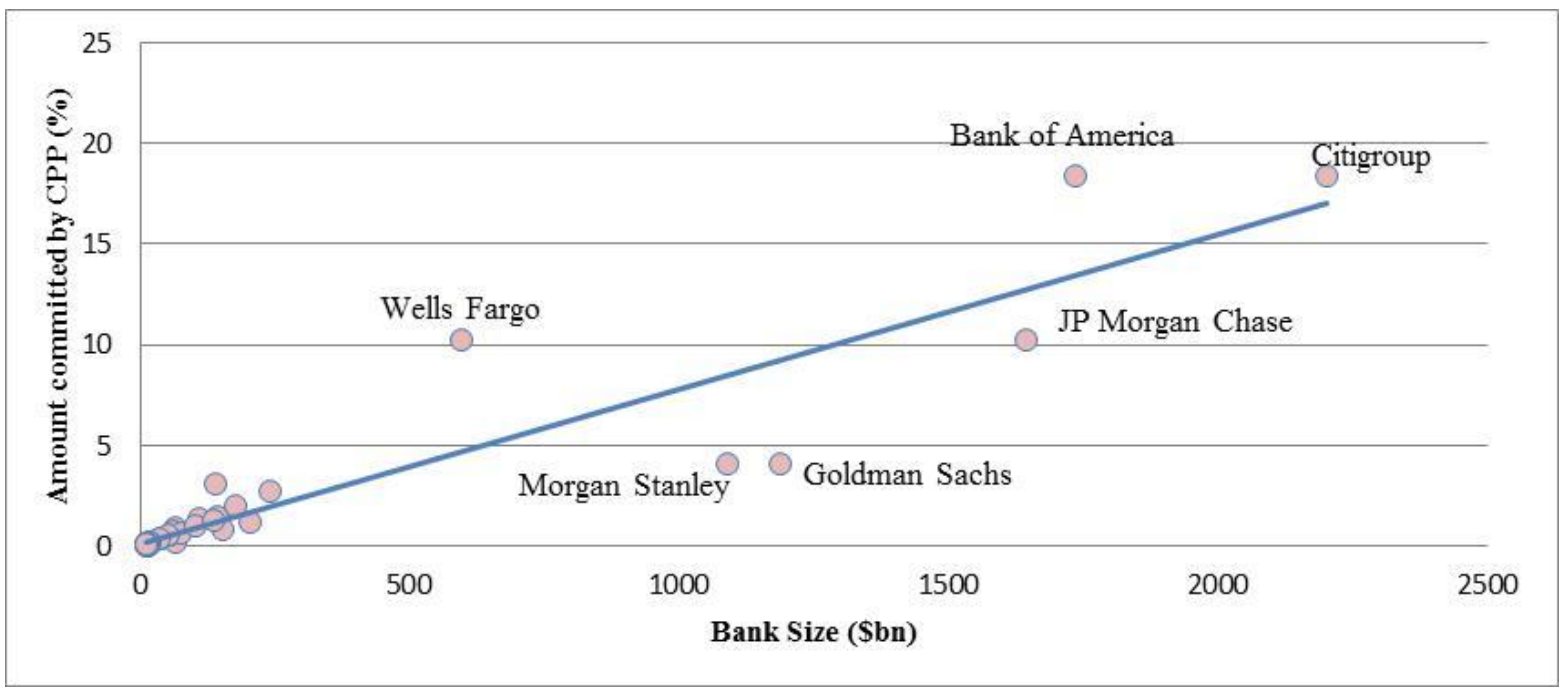

Figure 6. Bank level relationship between US government capital injections and bank size. This figure presents the scatterplot of the relative dollar amounts committed by the Capital Purchase Program (CPP) against bank size measured by total assets. 
Table 1. Rank correlations of systemic risk measures

Panel A of this Table reports the averages of pairwise rank correlations among the eight systemic risk measures studied in the paper, and bank size measured as total assets, during the whole sample period December 2003-December 2012. Rank correlations for the US (European) samples are reported on the upper (lower) triangular matrix. See Appendix 2 for detailed definitions of the systemic risk variables. Panel B shows the average values of the Herfindahl index and its normalised values for the US and European banking sectors.

\begin{tabular}{|c|c|c|c|c|c|c|c|c|c|}
\hline \multicolumn{10}{|c|}{ Panel A: Pairwise correlation } \\
\hline rSYR & & 0.52 & 0.22 & 0.36 & 0.47 & 0.27 & 0.10 & 0.23 & 0.94 \\
\hline SRISK & 0.90 & & 0.05 & 0.47 & 0.49 & 0.85 & -0.01 & 0.40 & 0.47 \\
\hline$\Delta \mathrm{CoVaR}$ & 0.40 & 0.35 & & -0.10 & -0.03 & -0.06 & 0.90 & -0.15 & 0.23 \\
\hline ES & 0.71 & 0.71 & 0.24 & & 0.49 & 0.49 & -0.14 & 0.98 & 0.30 \\
\hline sSYR & 0.50 & 0.59 & 0.05 & 0.51 & & 0.57 & -0.06 & 0.47 & 0.26 \\
\hline SSRISK & 0.49 & 0.69 & 0.15 & 0.49 & 0.73 & & -0.07 & 0.47 & 0.18 \\
\hline $\mathrm{s} \Delta \mathrm{CoVaR}$ & 0.32 & 0.29 & 0.95 & 0.18 & 0.05 & 0.18 & & -0.17 & 0.10 \\
\hline sES & 0.50 & 0.52 & 0.13 & 0.93 & 0.48 & 0.44 & 0.08 & & 0.16 \\
\hline Size & 0.99 & 0.89 & 0.41 & 0.70 & 0.46 & 0.48 & 0.33 & 0.48 & \\
\hline \multicolumn{10}{|c|}{ Panel B: Size Herfindahl Index } \\
\hline & \multicolumn{4}{|c|}{ US banks } & \multicolumn{4}{|c|}{ European banks } & \\
\hline & \multicolumn{2}{|c|}{ Herfindahl Index } & \multicolumn{2}{|c|}{ Normalised Herfindahl Index } & \multicolumn{2}{|c|}{ Herfindahl Index } & \multicolumn{2}{|c|}{ Normalised Herfindahl Index } & \\
\hline & \multicolumn{2}{|c|}{0.076} & \multicolumn{2}{|c|}{0.063} & \multicolumn{2}{|c|}{0.045} & \multicolumn{2}{|c|}{0.027} & \\
\hline
\end{tabular}




\section{Table 2. Summary statistics of banks' characteristics}

This Table shows summary statistics (panel A) and pairwise correlations among independent variables (panel B) for the banks in our sample. In panel B, pairwise correlations for US (European) banks are reported on the upper (lower) triangular matrix. Assets growth is the quarterly return of a bank's total assets; Tier 1 ratio is the ratio of tier 1 capital to risk weighted assets; Leverage is computed as total assets over total common equity; Asset Liquidity is the sum of available-for-sale securities and held-to-maturity securities over total assets, as in Landier, Sraer and Thesmar (2016); Return on Assets (ROA) is calculated as net income divided by total assets; the Deposit Ratio is deposits over total assets. Sample period: 2003Q4 to 2012Q4. All variables are winsorised at 5\% and 95\%.

\begin{tabular}{|c|c|c|c|c|c|c|c|}
\hline \multicolumn{8}{|c|}{ Panel A: Summary statistics } \\
\hline & $\begin{array}{l}\text { Total Assets } \\
\text { (bn USD) }\end{array}$ & $\begin{array}{l}\text { Assets } \\
\text { Growth } \\
(\%)\end{array}$ & $\begin{array}{c}\text { Tier } 1 \\
\text { Ratio } \\
(\%)\end{array}$ & Leverage & $\begin{array}{c}\text { Asset } \\
\text { Liquidity } \\
(\%)\end{array}$ & ROA $(\%)$ & $\begin{array}{c}\text { Deposit Ratio } \\
(\%)\end{array}$ \\
\hline Mean & 87.02 & 1.38 & 10.51 & 11.59 & 22.13 & 0.81 & 67.42 \\
\hline Median & 25.04 & 1.01 & 10.24 & 11.02 & 19.74 & 1.02 & 67.99 \\
\hline Max & 612.40 & 9.30 & 15.60 & 18.04 & 46.09 & 1.84 & 83.61 \\
\hline Min & 9.60 & -4.33 & 7.03 & 7.74 & 8.19 & -1.54 & 45.57 \\
\hline Std. Dev. & 146.70 & 3.38 & 2.38 & 2.68 & 10.37 & 0.83 & 10.30 \\
\hline Skewness & 2.70 & 0.59 & 0.47 & 0.87 & 0.89 & -1.45 & -0.42 \\
\hline Kurtosis & 9.51 & 3.05 & 2.37 & 3.15 & 2.99 & 4.77 & 2.54 \\
\hline \multirow[t]{3}{*}{ Obs. } & 1,837 & 1,837 & 1,837 & 1,837 & 1,837 & 1,837 & 1,837 \\
\hline & \multicolumn{7}{|c|}{ European Sample } \\
\hline & $\begin{array}{l}\text { Total Assets } \\
\text { (bn USD) }\end{array}$ & $\begin{array}{l}\text { Assets } \\
\text { Growth } \\
(\%)\end{array}$ & $\begin{array}{c}\text { Tier } 1 \\
\text { Ratio } \\
(\%)\end{array}$ & Leverage & $\begin{array}{c}\text { Asset } \\
\text { Liquidity } \\
(\%)\end{array}$ & ROA $(\%)$ & $\begin{array}{c}\text { Deposit Ratio } \\
(\%)\end{array}$ \\
\hline Mean & 763.67 & 1.48 & 9.85 & 25.46 & 28.13 & 0.42 & 40.32 \\
\hline Median & 435.07 & 1.10 & 9.20 & 23.09 & 26.33 & 0.47 & 39.58 \\
\hline Max & $2,558.15$ & 11.76 & 16.36 & 49.61 & 52.21 & 1.21 & 66.39 \\
\hline Min & 40.05 & -6.29 & 6.50 & 12.41 & 8.20 & -0.73 & 19.73 \\
\hline Std. Dev. & 775.93 & 4.45 & 2.64 & 10.22 & 13.32 & 0.47 & 13.91 \\
\hline Skewness & 1.06 & 0.46 & 0.97 & 0.88 & 0.31 & -0.63 & 0.24 \\
\hline Kurtosis & 2.97 & 2.97 & 3.20 & 2.96 & 1.98 & 3.37 & 1.92 \\
\hline Obs. & 1,081 & 1,081 & 1,081 & 1,081 & 1,081 & 1,081 & 1,081 \\
\hline \multicolumn{8}{|c|}{ Panel B: Pairwise correlations among independent variables } \\
\hline & $\begin{array}{c}\text { Log } \\
\text { (Total } \\
\text { Assets) } \\
\end{array}$ & $\begin{array}{l}\text { Assets } \\
\text { Growth }\end{array}$ & $\begin{array}{l}\text { Tier1 } \\
\text { Ratio }\end{array}$ & Leverage & $\begin{array}{c}\text { Asset } \\
\text { Liquidity }\end{array}$ & ROA & Deposit Ratio \\
\hline Log (Total assets) & & 0.02 & -0.18 & -0.10 & -0.02 & 0.02 & -0.37 \\
\hline Assets Growth & -0.02 & & -0.05 & 0.06 & 0.15 & 0.27 & -0.10 \\
\hline Tier1 Ratio & 0.19 & -0.10 & & -0.13 & 0.35 & -0.05 & 0.34 \\
\hline Leverage & 0.41 & -0.01 & -0.01 & & 0.15 & -0.21 & -0.20 \\
\hline Asset Liquidity & 0.52 & -0.04 & 0.25 & 0.37 & & 0.19 & -0.21 \\
\hline ROA & -0.20 & 0.24 & -0.13 & -0.24 & -0.25 & & -0.01 \\
\hline Deposit Ratio & -0.38 & 0.04 & -0.09 & -0.43 & -0.22 & 0.29 & \\
\hline
\end{tabular}


Table 3. Determinants of systemic risk measures

In this Table, we show results of panel regressions of bank specific systemic risk measures on (1 quarter) lagged bank characteristics. We employ 8 indicators of systemic risk. ES and sES are log-transformed by $\ln (E S+1)$ and $\ln (s E S * 1000,000+1)$, respectively. Explanatory variables include Size measured as log of total assets; Assets Growth given by the quarterly return of total assets; Tier1 ratio which is the ratio of tier1 capital to risk weighted assets; Leverage computed as total assets over total common equity; Liquidity equal to the sum of available for sale securities and held to maturity securities over total assets, as in Landier, Sraer and Thesmar (2016); Return on Assets (ROA) calculated as net income divided by total assets; and Deposit Ratio which is deposits over total assets. LC is a dummy that equals 1 if a bank's tier 1 ratio is less than $10 \%$. Sample period: 2003Q4 to 2012Q4. Variables are winsorised at the 5\% and 95\% levels. $* * *, * *$ and $*$ denote significance at the $1 \%$, 5\% and 10\% level. $\mathrm{t}$-values have been computed with White period (heteroscedasticity and autocorrelation robust) standard errors clustered at the firm level.

\begin{tabular}{|c|c|c|c|c|c|c|c|c|}
\hline \multirow[t]{3}{*}{ Panel A: US Banks } & \multicolumn{4}{|c|}{ Non-standardized } & \multicolumn{4}{|c|}{ Standardized } \\
\hline & (1) & (2) & (3) & (4) & $(5)$ & $(6)$ & (7) & $(8)$ \\
\hline & rSYR & SRISK & $\Delta \mathrm{CoVaR}$ & ES & sSYR & sSRISK & $\mathrm{s} \Delta \mathrm{CoVaR}$ & sES \\
\hline Constant & $-5.711 * * *$ & $-1.024 * * *$ & $2.213 * * *$ & -2.622 & $46.343 * * *$ & $-9.372 * *$ & $2.559 * * *$ & 0.239 \\
\hline Size & $0.648 * * *$ & $0.121 * * *$ & $0.066 * * *$ & $0.358 * * *$ & $1.530 *$ & 0.330 & 0.022 & 0.168 \\
\hline Assets Growth & 0.001 & -0.002 & $0.023 * *$ & $-0.041 * *$ & $-0.747 * * *$ & -0.014 & $0.018 * *$ & $-0.081 * * *$ \\
\hline Assets Growth ${ }^{2}$ & -0.001 & 0.000 & $-0.003 * *$ & $0.009 * * *$ & $0.123 * * *$ & -0.004 & $-0.002 * *$ & $0.017 * * *$ \\
\hline Tier 1 ratio & -0.031 & 0.003 & $-0.035 * *$ & 0.119 & 0.039 & $0.231 *$ & $-0.031 * *$ & $0.273 * *$ \\
\hline $\mathrm{LC}$ & -0.674 & -0.072 & -0.233 & 1.017 & 20.192 & $8.228 * * *$ & 0.002 & $3.624 *$ \\
\hline Tier 1 ratio*LC & 0.057 & -0.001 & 0.027 & -0.079 & -2.190 & $-0.858 * * *$ & 0.003 & -0.319 \\
\hline Leverage & 0.022 & $0.008 *$ & $-0.027 * *$ & 0.015 & $1.274 * * *$ & $0.535^{* * *}$ & $-0.027 * *$ & 0.061 \\
\hline Liquidity & 0.009 & -0.001 & -0.001 & -0.002 & 0.036 & -0.021 & -0.001 & -0.016 \\
\hline ROA & -0.118 & $-0.273 * * *$ & 0.058 & $-3.280 * * *$ & $-14.497 * * *$ & $-8.902 * * *$ & -0.181 & $-5.609 * * *$ \\
\hline Deposit Ratio & -0.009 & -0.002 & -0.001 & -0.018 & $-0.210^{*}$ & -0.038 & 0.001 & $-0.040 * *$ \\
\hline Time fixed effects & Yes & Yes & Yes & Yes & Yes & Yes & Yes & Yes \\
\hline Adjusted R-squared & 0.689 & 0.507 & 0.880 & 0.346 & 0.169 & 0.767 & 0.885 & 0.359 \\
\hline Adjusted R-squared with only FEs & -0.017 & 0.185 & 0.872 & 0.142 & 0.020 & 0.568 & 0.880 & 0.175 \\
\hline Adjusted R-squared with only Size & 0.659 & 0.301 & 0.020 & 0.077 & 0.022 & 0.024 & 0.010 & 0.013 \\
\hline Observations & & & & & 837 & & & \\
\hline
\end{tabular}




\begin{tabular}{|c|c|c|c|c|c|c|c|c|}
\hline \multirow[t]{3}{*}{ Panel B: European Banks } & \multicolumn{4}{|c|}{ Non-standardized } & \multicolumn{4}{|c|}{ Standardized } \\
\hline & (1) & (2) & (3) & (4) & (5) & (6) & (7) & (8) \\
\hline & rSYR & SRISK & $\Delta \mathrm{CoVaR}$ & ES & sSYR & sSRISK & $\mathrm{s} \Delta \mathrm{CoVaR}$ & sES \\
\hline Constant & $-18.224 * * *$ & $-17.423 * * *$ & 0.915 & $-13.072 * * *$ & $57.703 * * *$ & 1.824 & $1.658^{* * *}$ & -2.771 \\
\hline Size & $1.578 * * *$ & $1.535^{* * *}$ & $0.184 * * *$ & $1.312 * * *$ & $1.323^{*}$ & $0.353^{* * *}$ & $0.133^{* * *}$ & $0.516^{* *}$ \\
\hline Assets Growth & -0.005 & -0.008 & 0.002 & $-0.065^{* * *}$ & -0.146 & $-0.039 * * *$ & -0.004 & $-0.063 * *$ \\
\hline Assets Growth ${ }^{2}$ & $0.005 * *$ & 0.003 & -0.001 & $0.014 * * *$ & 0.015 & -0.002 & -0.000 & $0.014^{* * *}$ \\
\hline Tier 1 ratio & 0.036 & -0.002 & $-0.097 * * *$ & $0.183 * *$ & 0.209 & $-0.245^{*}$ & $-0.115 * * *$ & $0.220^{* *}$ \\
\hline $\mathrm{LC}$ & 0.601 & 0.334 & $-0.964 * *$ & 3.083 & 1.106 & -0.329 & $-1.168 * * *$ & $4.362 *$ \\
\hline Tier 1 ratio*LC & -0.082 & -0.064 & $0.099 * *$ & $-0.364 *$ & 0.231 & 0.034 & $0.116^{* * *}$ & $-0.466^{* *}$ \\
\hline Leverage & 0.026 & $0.063 * * *$ & -0.005 & $0.045^{*}$ & $0.381 * * *$ & $0.074 * * *$ & -0.003 & $0.050^{*}$ \\
\hline Liquidity & 0.001 & 0.000 & 0.001 & 0.003 & 0.006 & 0.005 & 0.001 & 0.006 \\
\hline ROA & 0.154 & -1.345 & 0.303 & $-3.862 * * *$ & -13.515 & $-4.194 * * *$ & 0.072 & $-4.238 * * *$ \\
\hline Deposit Ratio & -0.005 & -0.017 & -0.002 & $-0.025^{*}$ & -0.039 & $-0.021 * *$ & -0.002 & $-0.028^{*}$ \\
\hline Time fixed effects & Yes & Yes & Yes & Yes & Yes & Yes & Yes & Yes \\
\hline Adjusted R-squared & 0.789 & 0.727 & 0.754 & 0.616 & 0.305 & 0.716 & 0.754 & 0.419 \\
\hline Adjusted R-squared with only FEs & -0.030 & -0.027 & 0.695 & 0.070 & 0.018 & 0.348 & 0.699 & 0.138 \\
\hline Adjusted R-squared with only Size & 0.771 & 0.658 & 0.049 & 0.452 & 0.115 & 0.155 & 0.035 & 0.160 \\
\hline Observations & & & & 1,0 & & & & \\
\hline
\end{tabular}


Table 4. Prediction of large stock price contractions with pre-crisis systemic risk measures

This Table reports Probit regressions where the dependent variable equals 1 if a bank's stock price fall (F) is larger than $80 \%$ or $90 \%$ during the sub-prime crisis period (2007Q3 to 2009Q1). The dependent variable is always set to 1 for defaulted and delisted banks. Eight systemic risk measures (SRM), all lagged and measured in 2007Q2, are used as predictors. ES and sES are log-transformed by $\ln (E S+1)$ and $\ln (s E S *$ $1,000,000+1)$, respectively. Size is computed as log of total assets in 2007Q2. In the multivariate specifications involving non-standardised systemic risk measures, the component of Size that is orthogonal to systemic risk, instead of the Size itself, is used. Panel A (B) shows results for the US (Europe). Detailed definitions of the systemic risk measures are shown in Appendix 2.***,** and * denote significance at the 1\%, 5\% and $10 \%$ level. $t$-values have been computed with White (heteroscedasticity) standard errors. For specifications with significant systemic risk measure, the percentage of correctly classified banks is also reported, with the cup-off point being the ratio between the number of distressed banks and the total number of observations.

\begin{tabular}{|c|c|c|c|c|c|c|c|c|c|}
\hline \multirow[t]{2}{*}{ Panel A: US Banks } & \multicolumn{9}{|c|}{$\begin{array}{l}\text { Dependent variable: }=1 \text { if fall in stock price }>\mathrm{F}, 0 \text { otherwise } \\
\qquad \mathbf{F}=\mathbf{8 0} \%\end{array}$} \\
\hline & rSYR & SRSIK & $\Delta \mathrm{CoVaR}$ & ES & & rSYR & SRISK & $\Delta$ CoVaR & ES \\
\hline Non-standardised SRM & 7.00 & 4.23 & -15.60 & $0.23 * *$ & & 6.77 & 4.22 & -16.23 & $0.23 * * *$ \\
\hline Size & & & & & 0.14 & 0.11 & 0.11 & $0.24 * *$ & 0.08 \\
\hline Pseudo $\mathrm{R}^{2}$ & 0.015 & 0.013 & 0.001 & 0.072 & 0.019 & 0.019 & 0.021 & 0.038 & 0.077 \\
\hline$\%$ Distressed banks correctly classified & - & - & - & $37.5 \%$ & & - & - & - & $40.0 \%$ \\
\hline \multirow[t]{2}{*}{$\%$ All banks correctly classified } & - & - & - & $62.8 \%$ & & - & - & - & $61.5 \%$ \\
\hline & sSYR & sSRSIK & $\mathrm{s} \Delta \mathrm{CoVaR}$ & sES & & sSYR & sSRISK & $\mathrm{s} \Delta \mathrm{CoVaR}$ & sES \\
\hline Standardised SRM & $5.07 * * *$ & $32.89 * * *$ & -6.07 & $0.15^{* *}$ & & $4.92 * * *$ & $30.72 * * *$ & -58.50 & $0.14 * *$ \\
\hline Size & & & & & 0.14 & 0.05 & 0.10 & $0.18 *$ & 0.12 \\
\hline Pseudo $\mathrm{R}^{2}$ & 0.157 & 0.086 & 0.000 & 0.070 & 0.019 & 0.159 & 0.095 & 0.026 & 0.085 \\
\hline$\%$ Distressed banks correctly classified & $75.0 \%$ & $35.0 \%$ & - & $42.5 \%$ & & $75.0 \%$ & $40.0 \%$ & - & $52.5 \%$ \\
\hline$\%$ All banks correctly classified & $70.5 \%$ & $61.5 \%$ & - & $64.1 \%$ & & $70.5 \%$ & $62.8 \%$ & - & $65.4 \%$ \\
\hline No of Obs. & & & & & 78 & & & & \\
\hline No of distressed banks & & & & & 40 & & & & \\
\hline
\end{tabular}




\begin{tabular}{|c|c|c|c|c|c|c|c|c|c|}
\hline \multirow[t]{2}{*}{ Table 4 - Panel A - continued } & \multicolumn{9}{|c|}{$F=90 \%$} \\
\hline & rSYR & SRSIK & $\Delta \mathrm{CoVaR}$ & ES & & rSYR & SRISK & $\Delta \mathrm{CoVaR}$ & ES \\
\hline Non-standardised SRM & 7.26 & $6.99 *$ & -62.18 & $0.17 * *$ & & 7.21 & 6.98 & -70.16 & $0.17 * *$ \\
\hline Size & & & & & 0.12 & 0.04 & 0.02 & $0.32 * *$ & 0.07 \\
\hline Pseudo $\mathrm{R}^{2}$ & 0.018 & 0.037 & 0.012 & 0.048 & 0.015 & 0.018 & 0.037 & 0.074 & 0.053 \\
\hline$\%$ Distressed banks correctly classified & - & $17.2 \%$ & - & $41.4 \%$ & & - & - & - & $41.4 \%$ \\
\hline \multirow[t]{2}{*}{$\%$ All banks correctly classified } & - & $66.7 \%$ & - & $69.2 \%$ & & - & - & - & $64.1 \%$ \\
\hline & sSYR & sSRSIK & $\mathrm{s} \Delta \mathrm{CoVaR}$ & sES & & sSYR & sSRISK & $\mathrm{s} \Delta \mathrm{CoVaR}$ & sES \\
\hline Standardised SRM & $5.93 * * *$ & $35.99 * * *$ & -35.94 & $0.09 *$ & & $5.83 * * *$ & $34.65^{* * *}$ & -92.39 & $0.09 *$ \\
\hline Size & & & & & 0.12 & 0.04 & 0.08 & $0.19 *$ & 0.11 \\
\hline Pseudo $\mathrm{R}^{2}$ & 0.175 & 0.124 & 0.004 & 0.035 & 0.015 & 0.176 & 0.131 & 0.033 & 0.047 \\
\hline$\%$ Distressed banks correctly classified & $75.9 \%$ & $41.4 \%$ & - & $41.4 \%$ & & $75.9 \%$ & $44.8 \%$ & - & $51.7 \%$ \\
\hline$\%$ All banks correctly classified & $71.8 \%$ & $71.8 \%$ & - & $65.4 \%$ & & $71.8 \%$ & $71.8 \%$ & - & $64.1 \%$ \\
\hline No of Obs. & & & & & 78 & & & & \\
\hline No of distressed banks & & & & & 29 & & & & \\
\hline
\end{tabular}


Table 4 - continued

Panel B: European Banks

Dependent variable: $=1$ if fall in stock price $>\mathrm{F}, 0$ otherwise

Non-standardised SRM

$\mathrm{F}=\mathbf{8 0} \%$

Non-st

Pseudo R ${ }^{2}$

$\%$ Distressed banks correctly classified

$\%$ All banks correctly classified

Standardised SRM

Size

Pseudo R $\mathrm{R}^{2}$

$\%$ Distressed banks correctly classified

$\%$ All banks correctly classified

No of Obs.

No of distressed banks

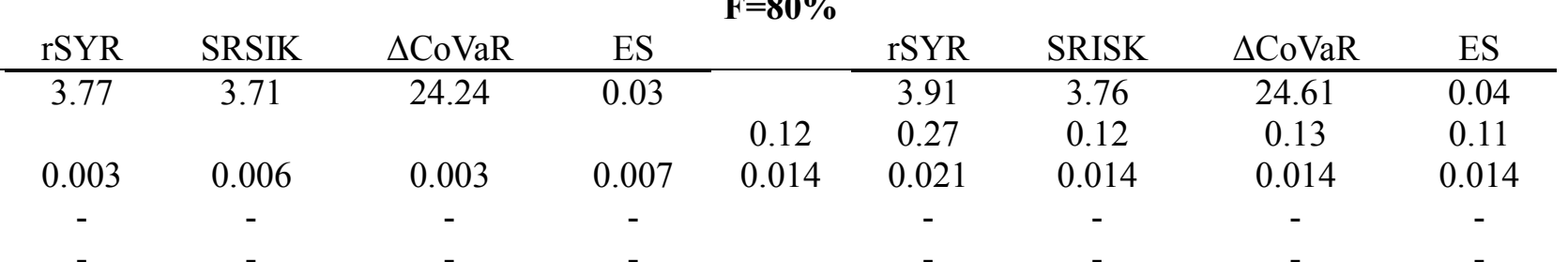

\begin{tabular}{cccccccccc} 
SSYR & sSRSIK & s $\Delta$ CoVaR & sES & & sSYR & sSRISK & s $\Delta$ CoVaR & sES \\
\hline $4.12 *$ & $22.17 * *$ & 30.81 & 0.04 & & 4.39 & $22.58 * *$ & 2.73 & 0.03 \\
& & & & 0.12 & -0.03 & -0.01 & 0.12 & 0.09 \\
0.059 & 0.089 & 0.004 & 0.011 & 0.014 & 0.060 & 0.089 & 0.014 & 0.017 \\
$80.0 \%$ & $65.0 \%$ & - & - & & - & $65.0 \%$ & - & - \\
$61.1 \%$ & $66.7 \%$ & - & - & & - & $66.7 \%$ & - & -
\end{tabular}

\begin{tabular}{|c|c|c|c|c|c|c|c|c|c|}
\hline \multirow[t]{3}{*}{ No of distressed banks } & \multirow{2}{*}{\multicolumn{9}{|c|}{$F=90 \%$}} \\
\hline & & & & & & & & & \\
\hline & rSYR & SRSIK & $\Delta \mathrm{CoVaR}$ & ES & & rSYR & SRISK & $\Delta \mathrm{CoVaR}$ & ES \\
\hline Non-standardised SRM & -1.15 & -0.63 & -23.85 & 0.01 & & -1.18 & -0.65 & -23.46 & 0.01 \\
\hline Size & & & & & -0.00 & 0.04 & 0.01 & 0.04 & -0.03 \\
\hline Pseudo $\mathrm{R}^{2}$ & 0.000 & 0.000 & 0.003 & 0.001 & 0.000 & 0.001 & 0.000 & 0.004 & 0.002 \\
\hline$\%$ Distressed banks correctly classified & - & - & - & - & & - & - & - & - \\
\hline \multirow[t]{2}{*}{$\%$ All banks correctly classified } & - & - & - & - & & - & - & - & - \\
\hline & sSYR & sSRSIK & $\mathrm{s} \Delta \mathrm{CoVaR}$ & sES & & sSYR & sSRISK & $\mathrm{s} \Delta \mathrm{CoVaR}$ & sES \\
\hline Standardised SRM & 3.92 & $18.05^{* *}$ & -28.86 & 0.03 & & 5.41 & $21.15^{* *}$ & -36.89 & 0.03 \\
\hline Size & & & & & -0.00 & -0.17 & -0.11 & 0.03 & -0.04 \\
\hline Pseudo $\mathrm{R}^{2}$ & 0.050 & 0.063 & 0.004 & 0.005 & 0.000 & 0.069 & 0.074 & 0.005 & 0.007 \\
\hline$\%$ Distressed banks correctly classified & - & $63.6 \%$ & - & - & & - & $72.7 \%$ & - & - \\
\hline$\%$ All banks correctly classified & - & $61.1 \%$ & - & - & & - & $68.5 \%$ & - & - \\
\hline No of Obs. & & & & & 54 & & & & \\
\hline No of distressed banks & & & & & 11 & & & & \\
\hline
\end{tabular}




\section{Table 5. Prediction of large stock price contractions with in-crisis systemic risk measures}

This Table reports Probit regressions where the dependent variable equals 1 if a bank's stock price fall (F) is larger than $80 \%$ or $90 \%$ during the sub-prime crisis period (2008Q2 to 2009Q1). The dependent variable is always set to 1 for defaulted and delisted banks. Eight systemic risk measures (SRM), all lagged and measured in 2008Q1, are used as predictors. ES and sES are log-transformed by $\ln (E S+1)$ and $\ln (s E S *$ $1,000,000+1)$, respectively. Size is computed as log of total assets in 2008Q1. In the multivariate specifications involving non-standardised systemic risk measures, the component of Size that is orthogonal to systemic risk, instead of the Size itself, is used. Panel A (B) shows results for the US (Europe). Detailed definitions of the systemic risk measures are shown in Appendix 2. ***, ** and * denote significance at the 1\%, 5\% and $10 \%$ level. t-values have been computed with White (heteroscedasticity) standard errors. For specifications with significant systemic risk measure, the percentage of correctly classified banks is also reported, with the cup-off point being the ratio between the number of distressed banks and the total number of observations.

\begin{tabular}{|c|c|c|c|c|c|c|c|c|c|}
\hline \multirow[t]{2}{*}{ Panel A: US Banks } & \multicolumn{9}{|c|}{$\begin{array}{l}\text { Dependent variable: }=1 \text { if fall in stock price }>\mathrm{F}, 0 \text { otherwise } \\
\qquad \mathbf{F}=\mathbf{8 0} \%\end{array}$} \\
\hline & rSYR & SRSIK & $\Delta \mathrm{CoVaR}$ & ES & & rSYR & SRISK & $\Delta \mathrm{CoVaR}$ & $\mathrm{ES}$ \\
\hline Non-standardised SRM & $13.49 * *$ & $17.40 * * *$ & $23.99 *$ & $0.28 * * *$ & & $13.30 * *$ & $18.36 * * *$ & $19.98 * *$ & $0.28 * * *$ \\
\hline Size & & & & & $0.22 * *$ & 0.09 & -0.12 & 0.14 & -0.04 \\
\hline Pseudo $\mathrm{R}^{2}$ & 0.072 & 0.125 & 0.077 & 0.304 & 0.064 & 0.075 & 0.130 & 0.095 & 0.305 \\
\hline$\%$ Distressed banks correctly classified & $44.4 \%$ & $50.0 \%$ & $44.4 \%$ & $77.8 \%$ & & $55.6 \%$ & $44.4 \%$ & $55.6 \%$ & $77.8 \%$ \\
\hline \multirow[t]{2}{*}{$\%$ All banks correctly classified } & $79.7 \%$ & $82.4 \%$ & $59.5 \%$ & $79.7 \%$ & & $74.3 \%$ & $81.1 \%$ & $68.9 \%$ & $78.4 \%$ \\
\hline & sSYR & sSRSIK & $\mathrm{s} \Delta \mathrm{CoVaR}$ & sES & & sSYR & sSRISK & $\mathrm{s} \Delta \mathrm{CoVaR}$ & sES \\
\hline Standardised SRM & $5.39 * * *$ & $34.83 * * *$ & $27.25 *$ & $0.21 * * *$ & & $5.13 * * *$ & $33.10 * * *$ & $19.51 *$ & $0.20 * * *$ \\
\hline Size & & & & & $0.22 * *$ & 0.17 & 0.09 & 0.13 & 0.17 \\
\hline Pseudo $\mathrm{R}^{2}$ & 0.212 & 0.301 & 0.093 & 0.264 & 0.064 & 0.246 & 0.308 & 0.109 & 0.292 \\
\hline$\%$ Distressed banks correctly classified & $72.2 \%$ & $88.9 \%$ & $61.1 \%$ & $88.9 \%$ & & $77.8 \%$ & $83.3 \%$ & $55.6 \%$ & $83.3 \%$ \\
\hline$\%$ All banks correctly classified & $67.6 \%$ & $77.0 \%$ & $63.5 \%$ & $75.7 \%$ & & $73.0 \%$ & $74.3 \%$ & $68.9 \%$ & $75.7 \%$ \\
\hline No of Obs. & & & & & 74 & & & & \\
\hline No of distressed banks & & & & & 18 & & & & \\
\hline
\end{tabular}




\begin{tabular}{|c|c|c|c|c|c|c|c|c|c|}
\hline \multirow[t]{2}{*}{ Table 5 - Panel A - continued } & \multicolumn{9}{|c|}{$\mathrm{F}=\mathbf{9 0} \%$} \\
\hline & rSYR & SRSIK & $\Delta \mathrm{CoVaR}$ & ES & & rSYR & SRISK & $\Delta \mathrm{CoVaR}$ & ES \\
\hline Non-standardised SRM & 8.45 & $11.24 *$ & $31.44 * *$ & $0.27 * * *$ & & $9.15^{*}$ & $11.79 * *$ & $24.93 * *$ & $0.27 * * *$ \\
\hline Size & & & & & $0.27 * *$ & $0.44 * *$ & 0.24 & 0.17 & 0.03 \\
\hline Pseudo $\mathrm{R}^{2}$ & 0.031 & 0.067 & 0.114 & 0.291 & 0.092 & 0.109 & 0.093 & 0.139 & 0.292 \\
\hline$\%$ Distressed banks correctly classified & - & $53.3 \%$ & $46.7 \%$ & $80.0 \%$ & & $73.3 \%$ & $66.7 \%$ & $60.0 \%$ & $80.0 \%$ \\
\hline \multirow[t]{2}{*}{$\%$ All banks correctly classified } & - & $83.8 \%$ & $64.9 \%$ & $78.4 \%$ & & $66.2 \%$ & $73.0 \%$ & $71.6 \%$ & $79.7 \%$ \\
\hline & sSYR & sSRSIK & $\mathrm{s} \Delta \mathrm{CoVaR}$ & sES & & sSYR & sSRISK & $\mathrm{s} \Delta \mathrm{CoVaR}$ & sES \\
\hline Standardised SRM & $5.92 * * *$ & $46.58 * * *$ & $35.06^{* *}$ & $0.21 * * *$ & & $5.75^{* * *}$ & $44.57 * * *$ & $24.13^{*}$ & $0.20^{* * *}$ \\
\hline Size & & & & & $0.27 * *$ & $0.23 * *$ & 0.15 & 0.16 & $0.22 *$ \\
\hline Pseudo $\mathrm{R}^{2}$ & 0.233 & 0.393 & 0.133 & 0.259 & 0.092 & 0.294 & 0.413 & 0.155 & 0.309 \\
\hline$\%$ Distressed banks correctly classified & $80.0 \%$ & $93.3 \%$ & $60.0 \%$ & $93.3 \%$ & & $86.7 \%$ & $86.7 \%$ & $60.0 \%$ & $80.0 \%$ \\
\hline$\%$ All banks correctly classified & $73.0 \%$ & $81.1 \%$ & $64.9 \%$ & $75.7 \%$ & & $74.3 \%$ & $79.7 \%$ & $73.0 \%$ & $74.3 \%$ \\
\hline No of Obs. & & & & & 74 & & & & \\
\hline No of distressed banks & & & & & 15 & & & & \\
\hline
\end{tabular}


Table 5 - continued

Dependent variable: $=1$ if fall in stock price $>\mathrm{F}, 0$ otherwise

Panel B: European Banks

$\mathrm{F}=\mathbf{8 0} \%$

Non-standardised SRM

\begin{tabular}{cccc} 
rSYR & SRSIK & $\Delta$ CoVaR & ES \\
\hline 1.19 & -1.66 & 21.98 & 0.03
\end{tabular}

Size

Pseudo $\mathrm{R}^{2}$

$\%$ Distressed banks correctly classified

$\%$ All banks correctly classified

\section{Standardised SRM}

Size

Pseudo $\mathrm{R}^{2}$

$\%$ Distressed banks correctly classified

$\%$ All banks correctly classified

No of Obs.

$\begin{array}{cccc}1.19 & -1.66 & 21.98 & 0.03 \\ 0.000 & 0.001 & 0.020 & 0.006 \\ - & - & - & - \\ - & - & - & -\end{array}$

(1)

No of distressed banks

\begin{tabular}{ccccccccc} 
SSYR & SSRSIK & s $\Delta$ CoVaR & sES & & SSYR & SSRISK & s $\Delta$ CoVaR & SES \\
\hline $7.99 * *$ & 12.56 & 29.71 & 0.02 & & $8.24 * *$ & 10.51 & 23.30 & 0.01 \\
& & & & 0.16 & -0.03 & 0.08 & 0.09 & 0.15 \\
0.125 & 0.040 & 0.033 & 0.003 & 0.023 & 0.126 & 0.045 & 0.038 & 0.023 \\
$75.0 \%$ & - & - & - & & $75.0 \%$ & - & - & - \\
$62.0 \%$ & - & - & - & & $62.0 \%$ & - & - & -
\end{tabular}

8

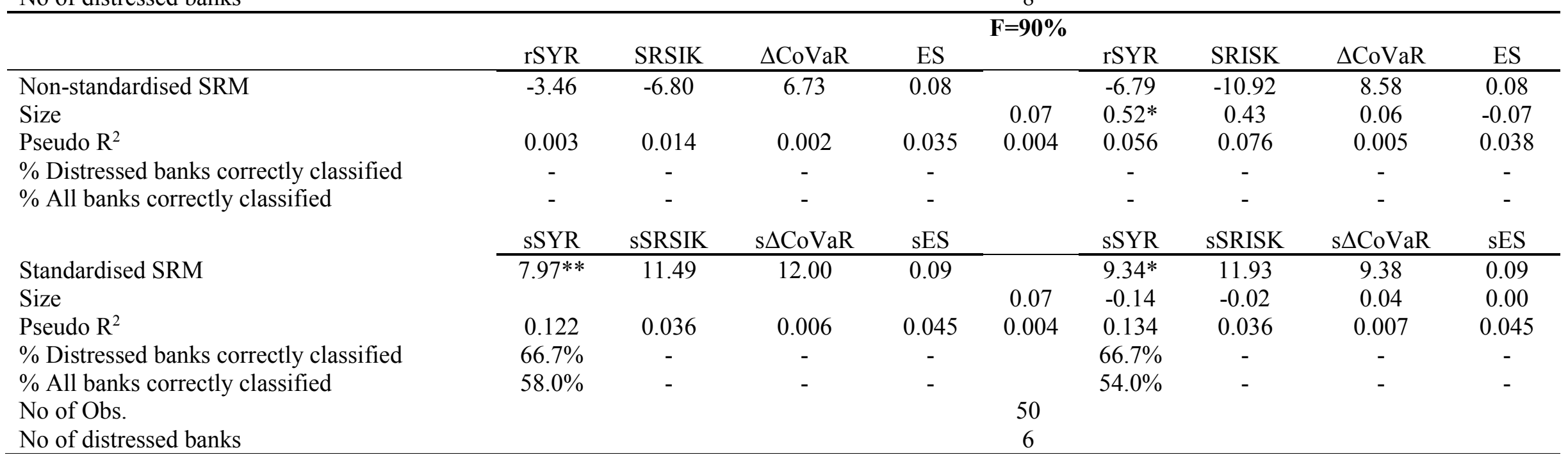




\section{Table 6. Prediction of bank failures}

This Table reports Probit regressions where the dependent variable equals 1 for defaulted and delisted banks during the sub-prime crisis period (2008Q2 to 2009Q1). Eight systemic risk measures (SRM) are variables of interest and are used as predictors. ES and sES are log-transformed by $\ln (E S+1)$ and $\ln (s E S * 1,000,000+1)$, respectively. Size is computed as log of total assets. In the multivariate specifications involving nonstandardised systemic risk measures, the component of Size that is orthogonal to systemic risk, instead of the Size itself, is used. Independent variables are lagged and measured in 2007Q2 and 2008Q1, respectively. Panel A (B) shows results for the US (Europe). Detailed definitions of the systemic risk measures are shown in Appendix 2. $* * *, * *$ and $*$ denote significance at the $1 \%, 5 \%$ and $10 \%$ level. t-values have been computed with White (heteroscedasticity) standard errors. For specifications with significant systemic risk measure, the percentage of correctly classified banks is also reported, with the cup-off point being the ratio between the number of distressed banks and the total number of observations.

\begin{tabular}{|c|c|c|c|c|c|c|c|c|c|}
\hline \multicolumn{10}{|l|}{ Panel A: US Banks } \\
\hline & \multicolumn{9}{|c|}{ Independent variables measured in 2007Q2 } \\
\hline & rSYR & SRSIK & $\Delta \mathrm{CoVaR}$ & ES & & rSYR & SRISK & $\Delta \mathrm{CoVaR}$ & $\mathrm{ES}$ \\
\hline Non-standardised SRM & 2.87 & 4.49 & -50.39 & $0.14^{*}$ & & 2.15 & 4.68 & -64.26 & $0.14^{*}$ \\
\hline Size & & & & & 0.17 & $0.44 * *$ & 0.14 & $0.48 * * *$ & 0.12 \\
\hline Pseudo $\mathrm{R}^{2}$ & 0.003 & 0.022 & 0.011 & 0.048 & 0.036 & 0.071 & 0.039 & 0.140 & 0.063 \\
\hline$\%$ Failed banks correctly classified & - & - & - & $36.4 \%$ & & - & - & - & $45.5 \%$ \\
\hline \multirow[t]{2}{*}{$\%$ All banks correctly classified } & - & - & - & $71.8 \%$ & & - & - & - & $68.0 \%$ \\
\hline & SSYR & sSRSIK & $\mathrm{s} \Delta \mathrm{CoVaR}$ & sES & & sSYR & SSRISK & $\mathrm{s} \Delta \mathrm{CoVaR}$ & sES \\
\hline Standardised SRM & 1.21 & 2.22 & -64.09 & 0.06 & & 0.78 & -1.37 & $-179.75^{*}$ & 0.05 \\
\hline Size & & & & & & 0.15 & $0.18 *$ & $0.35 * * *$ & 0.16 \\
\hline Pseudo $\mathrm{R}^{2}$ & 0.014 & 0.001 & 0.016 & 0.015 & & 0.042 & 0.037 & 0.113 & 0.045 \\
\hline$\%$ Failed banks correctly classified & - & - & - & - & & - & - & $63.6 \%$ & - \\
\hline$\%$ All banks correctly classified & - & - & - & - & & - & - & $69.2 \%$ & - \\
\hline No of Obs. & & & & & 78 & & & & \\
\hline No of distressed banks & & & & & 11 & & & & \\
\hline
\end{tabular}


Table 6 - Panel A - continued

Independent variables measured in 2008Q1

\begin{tabular}{|c|c|c|c|c|c|c|c|c|c|}
\hline & rSYR & SRSIK & $\Delta \mathrm{CoVaR}$ & ES & & rSYR & SRISK & $\Delta \mathrm{CoVaR}$ & ES \\
\hline Non-standardised SRM & 7.47 & 8.23 & $39.94 * *$ & $0.23 * * *$ & & 11.34 & $11.37 *$ & $34.85 * *$ & $0.23 * * *$ \\
\hline Size & & & & & $0.34 * * *$ & $0.86 * * *$ & $0.62 * * *$ & $0.19 *$ & 0.13 \\
\hline Pseudo $\mathrm{R}^{2}$ & 0.029 & 0.041 & 0.244 & 0.256 & 0.143 & 0.226 & 0.180 & 0.274 & 0.268 \\
\hline$\%$ Failed banks correctly classified & - & - & $57.1 \%$ & $85.7 \%$ & & - & $85.7 \%$ & $57.1 \%$ & $85.7 \%$ \\
\hline \multirow[t]{2}{*}{$\%$ All banks correctly classified } & - & - & $77.0 \%$ & $75.7 \%$ & & - & $71.6 \%$ & $74.3 \%$ & $78.4 \%$ \\
\hline & sSYR & sSRSIK & $\mathrm{s} \Delta \mathrm{CoVaR}$ & sES & & sSYR & sSRISK & $\mathrm{s} \Delta \mathrm{CoVaR}$ & sES \\
\hline Standardised SRM & $3.59 * *$ & $22.12 * * *$ & $40.12 * *$ & $0.15 * *$ & & $3.48 *$ & $17.74 * *$ & $29.83 * *$ & $0.13 *$ \\
\hline Size & & & & & & $0.29 * * *$ & $0.25 * *$ & $0.20 * *$ & $0.27 * * *$ \\
\hline Pseudo $\mathrm{R}^{2}$ & 0.125 & 0.145 & 0.255 & 0.162 & & 0.226 & 0.213 & 0.290 & 0.247 \\
\hline$\%$ Failed banks correctly classified & $85.7 \%$ & $85.7 \%$ & $57.1 \%$ & $85.7 \%$ & & $85.7 \%$ & $85.7 \%$ & $57.1 \%$ & $85.7 \%$ \\
\hline$\%$ All banks correctly classified & $66.2 \%$ & $68.9 \%$ & $79.7 \%$ & $64.9 \%$ & & $73.0 \%$ & $75.7 \%$ & $75.7 \%$ & $74.3 \%$ \\
\hline No of Obs. & & & & & 74 & & & & \\
\hline No of distressed banks & & & & & 7 & & & & \\
\hline
\end{tabular}


Table 6 - continued

Independent variables measured in 2007Q2

Panel B: European Banks

\begin{tabular}{|c|c|c|c|c|c|c|c|c|}
\hline rSYR & SRSIK & $\Delta \mathrm{CoVaR}$ & ES & & rSYR & SRISK & $\Delta \mathrm{CoVaR}$ & ES \\
\hline 0.38 & 0.54 & -40.72 & 0.03 & & 0.40 & 0.57 & -40.17 & 0.03 \\
\hline & & & & -0.00 & -0.03 & -0.02 & 0.08 & -0.07 \\
\hline 0.000 & 0.000 & 0.009 & 0.006 & 0.000 & 0.000 & 0.000 & 0.014 & 0.009 \\
\hline - & - & - & - & & - & - & - & - \\
\hline - & - & - & - & & - & - & - & - \\
\hline sSYR & sSRSIK & $\mathrm{s} \Delta \mathrm{CoVaR}$ & sES & & sSYR & sSRISK & $\mathrm{s} \Delta \mathrm{CoVaR}$ & sES \\
\hline 3.69 & $21.07 * *$ & -49.00 & 0.05 & & 5.01 & $24.42 * *$ & -64.50 & 0.06 \\
\hline & & & & & -0.15 & -0.13 & 0.07 & -0.06 \\
\hline 0.045 & 0.086 & 0.011 & 0.016 & & 0.062 & 0.098 & 0.014 & 0.019 \\
\hline- & $70.0 \%$ & - & - & & - & $70.0 \%$ & - & - \\
\hline- & $64.8 \%$ & - & - & & - & $70.4 \%$ & - & - \\
\hline
\end{tabular}

Size

Pseudo R ${ }^{2}$

$\%$ Failed banks correctly classified

$\%$ All banks correctly classified

\section{Standardised SRM}

Size

Pseudo R ${ }^{2}$

$\%$ Failed banks correctly classified

$\%$ All banks correctly classified

No of Obs.

No of distressed banks

Independent variables measured in 2008Q1

Non-standardised SRM

Size

Pseudo $\mathrm{R}^{2}$

$\%$ Failed banks correctly classified

$\%$ All banks correctly classified

\section{Standardised SRM}

Size

Pseudo $\mathrm{R}^{2}$

$\%$ Failed banks correctly classified

$\%$ All banks correctly classified

No of Obs.

No of distressed banks

\begin{tabular}{|c|c|c|c|c|c|c|c|c|}
\hline rSYR & SRSIK & $\Delta \mathrm{CoVaR}$ & ES & & rSYR & SRISK & $\Delta \mathrm{CoVaR}$ & $\mathrm{ES}$ \\
\hline \multirow[t]{2}{*}{-0.96} & -5.05 & 0.24 & 0.09 & & -2.57 & -7.98 & 4.04 & 0.09 \\
\hline & & & & 0.09 & 0.43 & 0.41 & 0.11 & -0.05 \\
\hline 0.000 & 0.008 & 0.000 & 0.047 & 0.007 & 0.041 & 0.069 & 0.009 & 0.048 \\
\hline- & - & - & - & & - & - & - & - \\
\hline - & - & - & - & & - & - & - & - \\
\hline sSYR & sSRSIK & $\mathrm{s} \Delta \mathrm{CoVaR}$ & sES & & sSYR & sSRISK & $\mathrm{s} \Delta \mathrm{CoVaR}$ & sES \\
\hline \multirow[t]{2}{*}{$10.69 *$} & 10.97 & 8.21 & 0.09 & & 11.87 & 10.63 & 3.60 & 0.09 \\
\hline & & & & & -0.13 & 0.02 & 0.08 & 0.03 \\
\hline 0.165 & 0.034 & 0.003 & 0.051 & & 0.175 & 0.035 & 0.008 & 0.052 \\
\hline $80.0 \%$ & - & - & - & & - & - & - & - \\
\hline \multirow[t]{2}{*}{$62.0 \%$} & - & - & - & & - & - & - & - \\
\hline & & & & $\begin{array}{c}50 \\
5\end{array}$ & & & & \\
\hline
\end{tabular}




\section{Table 7. Relationship between bailouts and banks' systemic risk}

This Table reports Probit regressions where the dependent variable equals 1 if a bank was bailed out during the crisis. Size, expressed as log of total assets, and eight systemic risk measures (SRM), all computed in 2007Q2, are used as predictors. ES and sES are log-transformed by $l n(E S+$ 1) and $\ln (s E S * 1,000,000+1)$, respectively. In the multivariate specifications involving non-standardised systemic risk measures, the component of Size that is orthogonal to systemic risk, instead of the Size itself, is used. Panel A (B) shows results for the US (Europe). Detailed definitions of the systemic risk measures are shown in Appendix 2. $* * *, * *$ and $*$ denote significance at the $1 \%, 5 \%$ and $10 \%$ level. t-values have been computed with White (heteroscedasticity) standard errors. For specifications with significant systemic risk measure, the percentage of correctly classified banks is also reported, with the cup-off point being the ratio between the number of distressed banks and the total number of observations.

\begin{tabular}{|c|c|c|c|c|c|c|c|c|c|}
\hline \multicolumn{10}{|l|}{ Panel A: US banks } \\
\hline & rSYR & SRISK & $\Delta \mathrm{CoVaR}$ & ES & & rSYR & SRISK & $\Delta \mathrm{CoVaR}$ & ES \\
\hline Non-standardised SRM & $0.48 * * *$ & $0.13 * * *$ & $1.69 * *$ & $0.16^{* *}$ & & $0.43 * * *$ & $0.14 * * *$ & $1.39 * *$ & $0.21 * *$ \\
\hline Size & & & & & $0.64 * * *$ & 0.22 & $0.62 * * *$ & $0.83 * * *$ & $0.62 * * *$ \\
\hline Pseudo $\mathrm{R}^{2}$ & 0.410 & 0.138 & 0.080 & 0.053 & 0.376 & 0.419 & 0.377 & 0.404 & 0.383 \\
\hline$\%$ Failed banks correctly classified & $62.5 \%$ & $31.3 \%$ & $62.5 \%$ & $43.8 \%$ & & $62.5 \%$ & $75.0 \%$ & $81.3 \%$ & $81.3 \%$ \\
\hline \multirow[t]{2}{*}{$\%$ All banks correctly classified } & $88.5 \%$ & $83.3 \%$ & $64.1 \%$ & $74.4 \%$ & & $84.6 \%$ & $79.5 \%$ & $83.3 \%$ & $82.1 \%$ \\
\hline & sSYR & sSRISK & $\mathrm{s} \Delta \mathrm{CoVaR}$ & $\mathrm{sES}$ & & sSYR & sSRISK & $\mathrm{s} \Delta \mathrm{CoVaR}$ & sES \\
\hline Standardised SRM & 0.01 & 0.11 & 1.02 & 0.07 & & -0.01 & 0.04 & -1.34 & 0.09 \\
\hline Size & & & & & $0.64 * * *$ & $0.68 * * *$ & $0.63 * * *$ & $0.76 * * *$ & $0.66 * * *$ \\
\hline Pseudo $\mathrm{R}^{2}$ & 0.011 & 0.016 & 0.029 & 0.022 & 0.376 & 0.384 & 0.378 & 0.401 & 0.399 \\
\hline$\%$ Failed banks correctly classified & - & - & - & - & & - & - & - & - \\
\hline$\%$ All banks correctly classified & - & - & - & - & & - & - & - & - \\
\hline No of Obs. & & & & & 78 & & & & \\
\hline
\end{tabular}


Table 7 - continued

Panel B: European banks

Non-standardised SRM

Size

Pseudo $\mathrm{R}^{2}$

$\%$ Failed banks correctly classified

$\%$ All banks correctly classified

\section{Standardised SRM}

Size

Pseudo $\mathrm{R}^{2}$

$\%$ Failed banks correctly classified

$\%$ All banks correctly classified No of Obs.

\begin{tabular}{|c|c|c|c|c|c|c|c|c|}
\hline rSYR & SRISK & $\Delta \mathrm{CoVaR}$ & $\mathrm{ES}$ & & rSYR & SRISK & $\Delta \mathrm{CoVaR}$ & $\mathrm{ES}$ \\
\hline \multirow{2}{*}{$0.28 * * *$} & $0.14 *$ & $1.24 * *$ & 0.04 & & $0.30 * * *$ & $0.17 * * *$ & $1.29 * *$ & 0.06 \\
\hline & & & & $0.52 * * *$ & 0.40 & $0.52 * *$ & $0.54 * * *$ & $0.79 * * *$ \\
\hline 0.182 & 0.102 & 0.069 & 0.012 & 0.206 & 0.209 & 0.206 & 0.206 & 0.267 \\
\hline $64.7 \%$ & $52.9 \%$ & $82.4 \%$ & - & & $70.6 \%$ & $70.6 \%$ & $70.6 \%$ & - \\
\hline $75.9 \%$ & $75.9 \%$ & $70.4 \%$ & - & & $72 . .2 \%$ & $70.4 \%$ & $70.4 \%$ & - \\
\hline sSYR & sSRISK & $\mathrm{s} \Delta \mathrm{CoVaR}$ & sES & & sSYR & sSRISK & $\mathrm{s} \Delta \mathrm{CoVaR}$ & sES \\
\hline \multirow[t]{2}{*}{0.05} & 0.09 & $1.24 * *$ & 0.01 & & -0.00 & -0.13 & 0.06 & $-0.12 *$ \\
\hline & & & & $0.52 * * *$ & $0.54 * * *$ & $0.63 * * *$ & $0.52 * * *$ & $0.70 * * *$ \\
\hline 0.072 & 0.014 & 0.054 & 0.001 & 0.206 & 0.206 & 0.222 & 0.206 & 0.259 \\
\hline- & - & & - & & - & - & - & $88.2 \%$ \\
\hline \multirow[t]{2}{*}{-} & - & & - & & - & - & - & $79.6 \%$ \\
\hline & & & & 54 & & & & \\
\hline
\end{tabular}




\section{Appendix 1: Bank list}

The table contains firm level information for all the financial firms in our sample. We report the book value of total assets just before the sub-prime crisis (December 2006) and at the end of the sample period (December 2012). Banks are labelled with a "Y" if they are identified as systemically important financial firms (SIFIs) in 2011 by the Financial Stability Board (FSB). For US banks, a "Y" in the last column of Panel A indicates participation in the US Treasury's Capital Purchase Program (CPP) in 2008. Firms with an asterisk defaulted or were acquired during our sample period.

\begin{tabular}{|c|c|c|c|c|}
\hline \multicolumn{5}{|l|}{ Panel A: United States } \\
\hline \multirow[t]{2}{*}{ Bank Name } & \multicolumn{2}{|c|}{ Bank Total Assets (bn USD) } & \multirow[t]{2}{*}{ SIFIs (2011) } & \multirow[t]{2}{*}{ CPP (2008) } \\
\hline & Dec-06 & Dec-12 & & \\
\hline Citigroup & 1,884 & 1,865 & Y & $\mathrm{Y}$ \\
\hline Bank of America & 1,460 & 2,210 & $\mathrm{Y}$ & $\mathrm{Y}$ \\
\hline JPMorgan Chase & 1,352 & 2359 & $\mathrm{Y}$ & $\mathrm{Y}$ \\
\hline Morgan Stanley & 1,121 & 781 & $\mathrm{Y}$ & $\mathrm{Y}$ \\
\hline Fannie Mae & 844 & 3,222 & & \\
\hline Merrill Lynch & 841 & 603 & & \\
\hline Goldman Sachs & 838 & 939 & Y & $\mathrm{Y}$ \\
\hline Freddie Mac & 813 & 1,990 & & \\
\hline Wachovia* & 707 & -- & & \\
\hline Lehman Brothers* & 504 & -- & & \\
\hline Wells Fargo \& Co & 482 & 1,423 & $\mathrm{Y}$ & $\mathrm{Y}$ \\
\hline Bear Stearns* & 350 & -- & & \\
\hline Washington Mutual* & 346 & -- & & \\
\hline US Bancorp & 219 & 354 & & Y \\
\hline Countrywide Financial* & 200 & -- & & \\
\hline Suntrust banks & 182 & 173 & & Y \\
\hline Regions Financial & 143 & 121 & & $\mathrm{Y}$ \\
\hline National City Corp* & 140 & -- & & \\
\hline $\mathrm{BB} \& \mathrm{~T}$ & 121 & 184 & & $\mathrm{Y}$ \\
\hline State Street Corp & 107 & 223 & Y & $\mathrm{Y}$ \\
\hline Bank NY Mellon & 103 & 359 & Y & $\mathrm{Y}$ \\
\hline PNC Financial & 102 & 305 & & $\mathrm{Y}$ \\
\hline Fifth Third Banc & 101 & 122 & & $\mathrm{Y}$ \\
\hline Keycorp & 92 & 89 & & $\mathrm{Y}$ \\
\hline Santander Holding USA & 90 & 86 & & \\
\hline Northern Trust & 61 & 97 & & $\mathrm{Y}$ \\
\hline Comerica Inc & 58 & 65 & & $\mathrm{Y}$ \\
\hline M\&T Bank Corp & 57 & 83 & & $\mathrm{Y}$ \\
\hline Marshall \& Ilsley Corp* & 56 & -- & & $\mathrm{Y}$ \\
\hline E Trade Financial Corp & 54 & 47 & & \\
\hline MUFG Americas Holdings & 53 & 97 & & \\
\hline Schwab (Charles) Corp & 49 & 134 & & \\
\hline
\end{tabular}


Panel A continued

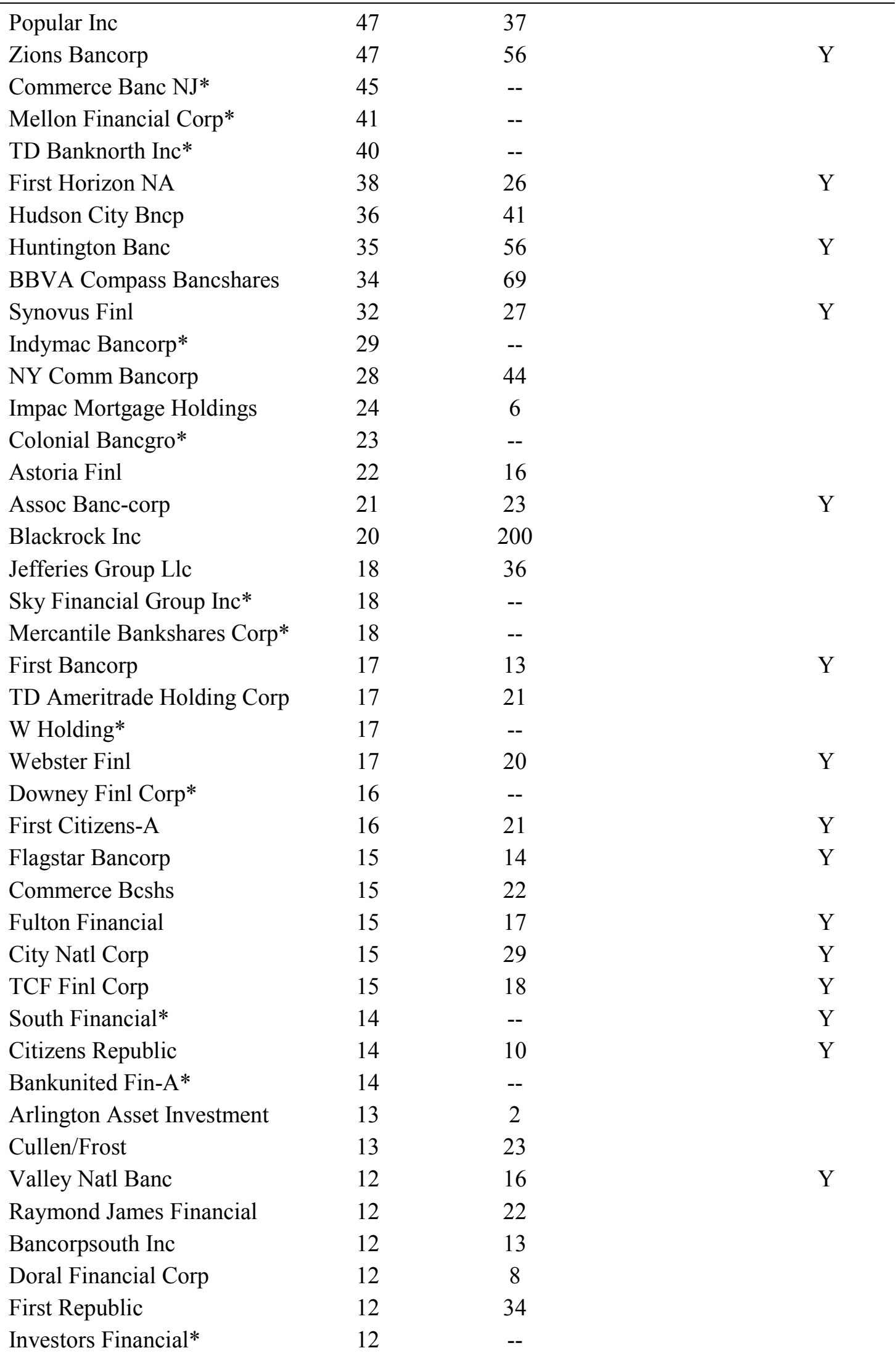


Panel A continued

\begin{tabular}{|c|c|c|c|}
\hline Wilmington Trust Corp* & 11 & -- & $\mathrm{Y}$ \\
\hline Maf Bancorp Inc* & 11 & -- & \\
\hline Intl Bancshares Corp & 11 & 12 & \\
\hline East West Bancorp Inc & 11 & 23 & \\
\hline People's United & 11 & 30 & \\
\hline Bank of Hawaii Corp & 11 & 14 & \\
\hline Firstmerit Corp & 10 & 15 & $\mathrm{Y}$ \\
\hline Whitney Holding Corp* & 10 & -- & $\mathrm{Y}$ \\
\hline Corus Bankshares Inc* & 10 & -- & \\
\hline \multicolumn{4}{|l|}{ Panel B: Europe } \\
\hline \multirow{2}{*}{ Bank Name } & \multicolumn{2}{|c|}{ Bank Total Asset (bn USD) } & \multirow{2}{*}{ SIFIs (2011) } \\
\hline & Dec-06 & Dec-12 & \\
\hline UBS & 1,963 & 1,375 & $\mathrm{Y}$ \\
\hline Barclays Plc & 1,950 & 2,410 & $\mathrm{Y}$ \\
\hline BNP Paribas & 1,899 & 2,514 & $\mathrm{Y}$ \\
\hline HSBC & 1,860 & 2,692 & $\mathrm{Y}$ \\
\hline RBS & 1,705 & 2,121 & $\mathrm{Y}$ \\
\hline ING Group & 1,617 & 1,532 & $\mathrm{Y}$ \\
\hline Deutsche Bank-RG & 1,485 & 2,653 & $\mathrm{Y}$ \\
\hline ABN-AMRO Holdings* & 1,301 & -- & \\
\hline Societe Generale & 1,262 & 1,649 & $\mathrm{Y}$ \\
\hline HBOS Plc* & 1,156 & - & \\
\hline Banco Santander & 1,100 & 1,674 & $\mathrm{Y}$ \\
\hline Unicredit Spa & 1,085 & 1,222 & $\mathrm{Y}$ \\
\hline Credit Suiss-Reg & 1,028 & 1,010 & \\
\hline Commerzbank & 802 & 838 & Y \\
\hline Dexia SA & 748 & 471 & $\mathrm{Y}$ \\
\hline Lloyds Banking & 672 & 1,495 & $\mathrm{Y}$ \\
\hline Bayerische Hypo \& Vereinsbk* & 670 & -- & \\
\hline Natixis & 605 & 696 & \\
\hline BBVA & 543 & 841 & \\
\hline Nordea & 458 & 893 & $\mathrm{Y}$ \\
\hline KBC Group & 429 & 339 & \\
\hline Intesa Sanpaolo & 385 & 887 & \\
\hline SEB AB-A & 282 & 377 & \\
\hline $\mathrm{CIC}$ & 282 & 311 & \\
\hline Standard Chartered & 266 & 637 & \\
\hline Svenska Han-A & 261 & 367 & \\
\hline Erste Group Bank & 240 & 282 & \\
\hline Allied Irish Bank & 210 & 162 & \\
\hline Swedbank AB-A & 198 & 283 & \\
\hline Northern Rock* & 198 & -- & \\
\hline
\end{tabular}


Panel B continued

\begin{tabular}{lcc} 
Landesbank Berli* & 187 & -- \\
Capitalia Spa* & 181 & -- \\
Alliance \& Leice* & 134 & -- \\
Banco Popular & 121 & 208 \\
Banco Com Port-R & 104 & 119 \\
Natl Bank Greece & 102 & 138 \\
Banco BPM Spa & 91 & 174 \\
Bradford \& Bing* & 88 & -- \\
Deutsche Boerse AG & 86 & 286 \\
Banco Espirito-R & 78 & 111 \\
Mediobanca & 70 & 105 \\
Banca Popolare Italiana* & 62 & -- \\
Bankinter & 61 & 76 \\
Banca Popolare Di Milano & 53 & 69 \\
BHW Holding AG* & 51 & -- \\
Banco BPI SA & 47 & 59 \\
Piraeus Bank SA & 41 & 92 \\
Crcam Paris D'ile France & 37 & 46 \\
Credito Emiliano Spa & 32 & 41 \\
Banco Pastor* & 32 & -- \\
Emporiki Bank of Greece SA* & 30 & -- \\
Banque Cantonale Vaudoise & 30 & 44 \\
Gam Holding Ltd & 29 & 3 \\
Banco De Valencia SA & 21 & 29 \\
Kensington Group Plc* & 16 & -- \\
\hline
\end{tabular}


Appendix 2: Variable definitions ${ }^{26}$

Panel A: Systemic risk measures
paper. It is deasure of a financial institution's systemic risk proposed in this
rSYR $\quad r S Y R_{i, t}=\frac{\operatorname{Max}\left(0, S Y R_{i, t}\right)}{\sum_{i}\left(S Y R_{i, t} \mid S Y R_{i, t}>0\right)}$, where
Max $\left(0, S Y R_{i, t}\right)$ is firm $i$ 's total expected capital shortfall conditional on
a financial crisis and $\sum_{i}\left(S Y R_{i, t} \mid S Y R_{i, t}>0\right)$ is the total amount of
expected capital shortfall in the financial system during a crisis.
Market measure of a financial institution's systemic risk based on
Brownlees and Engle (2017). It is defined as: $S R I S K_{i, t}=\frac{M a x\left(0, C S_{i, t}\right)}{\sum_{i}\left(C S_{i, t} \mid C S_{i, t}>0\right)}$,
where Max $\left(0, C S_{i, t}\right)$ is firm $i$ 's total expected capital shortfall
conditional on a financial crisis and $\sum_{i}\left(C S_{i, t} \mid C S_{i, t}>0\right)$ is the total
amount of expected capital shortfall in the financial system during a crisis.

26 SRISK and $\triangle \mathrm{CoVaR}$ are estimated using the Matlab codes obtained from http://www.runmycode.org/companion/view/175. Please refer to Benoit et al. (2014) for details. We thank the authors for sharing their software. To validate the output of the codes we have checked $\Delta \mathrm{CoVaR}$ against our own estimates on a sample of US and European banks and compared SRISK with estimates available from the New York Stern Business School Volatility Institute at https://vlab.stern.nyu.edu. 
where $B_{t}^{i}$ is the book value of total debts, $\sigma$ is asset volatility, $V_{t}^{i}$ is the market value of total assets and $d_{t}=\frac{\ln \left(\frac{v_{t}^{i}}{B_{t}^{i}}\right)+\frac{\sigma^{2}}{2} T}{\sigma \sqrt{T}}$.

A nice property of $\boldsymbol{E} \boldsymbol{S}_{\boldsymbol{t}}$ is that the sum of its elements is equal to $z_{t}$. Therefore $E S_{i, t}$ represents the contribution of bank $i$ to the overall volatility in the expected shortfall of the banking system.

\begin{tabular}{ll}
\hline \multirow{2}{*}{ sSYR } & Standardized version of rSYR. It is defined as: $s S Y R_{i, t}=\frac{{\operatorname{Max}\left(0, S Y R_{i, t}\right)}_{T A_{i, t}}}{}$ \\
& where $M a x\left(0, S Y R_{i, t}\right)$ is firm $i$ 's total expected capital shortfall \\
& conditional on a financial crisis at time $t$ and $T A_{i, t}$ is the total asset value \\
& of firm $i$ at time $t$.
\end{tabular}




\section{Appendix 3: Rankings of systemically important banks}

The Table shows the rankings of systemically important banks in the US (panel A) and Europe (panel B) at year-end 2011 according to eight systemic risk measures. A bank is included in the table if it is one of the top 20 riskiest banks as of 2011Q4 according to either rSYR or sSYR. Asset value is measured as of 2011Q4 and is in billion US Dollars for US banks and in billion Euros for European banks. Banks included in the Financial Stability Board (FSB) list of "systemically important financial institutions" are labelled with a "Y". See Appendix 2 for systemic risk variable definitions.

\begin{tabular}{|c|c|c|c|c|c|c|c|c|c|c|}
\hline \multirow{2}{*}{$\begin{array}{c}\text { Panel A: United States } \\
\text { Bank }\end{array}$} & \multirow{2}{*}{ Asset value } & \multicolumn{8}{|c|}{2011 Systemic Risk Rankings } & \multirow{2}{*}{ FSB } \\
\hline & & rSYR & SRISK & $\Delta \mathrm{CoVaR}$ & ES & sSYR & sSRISK & $\mathrm{s} \Delta \mathrm{CoVaR}$ & sES & \\
\hline Fannie Mae & 3,211 & 1 & 1 & 54 & 2 & 2 & 2 & 55 & 12 & \\
\hline Freddie Mac & 2,147 & 2 & 2 & 52 & 4 & 1 & 1 & 53 & 11 & \\
\hline JPMorgan Chase & 2,266 & 3 & 4 & 3 & 7 & 12 & 14 & 4 & 14 & $\mathrm{Y}$ \\
\hline Bank of America & 2,129 & 4 & 3 & 35 & 5 & 6 & 6 & 44 & 10 & $\mathrm{Y}$ \\
\hline Citigroup & 1,874 & 5 & 5 & 4 & 1 & 8 & 8 & 9 & 8 & $\mathrm{Y}$ \\
\hline Wells Fargo \& Co & 1,314 & 6 & 8 & 21 & 35 & 19 & 41 & 37 & 44 & $\mathrm{Y}$ \\
\hline Goldman Sachs & 923 & 7 & 6 & 22 & 8 & 9 & 13 & 36 & 18 & $\mathrm{Y}$ \\
\hline Morgan Stanley & 750 & 8 & 7 & 1 & 3 & 4 & 5 & 1 & 5 & $\mathrm{Y}$ \\
\hline US Bancorp & 340 & 9 & 54 & 29 & 47 & 24 & 49 & 30 & 47 & \\
\hline Bank NY Mellon & 325 & 10 & 9 & 2 & 17 & 45 & 21 & 2 & 23 & $\mathrm{Y}$ \\
\hline PNC Financial & 271 & 11 & 14 & 36 & 48 & 33 & 42 & 41 & 49 & \\
\hline State Street Corp & 217 & 12 & 12 & 28 & 12 & 39 & 32 & 23 & 15 & $\mathrm{Y}$ \\
\hline $\mathrm{BB} \& \mathrm{~T}$ & 175 & 13 & 13 & 26 & 27 & 20 & 37 & 19 & 35 & \\
\hline Blackrock & 180 & 14 & 25 & 23 & 6 & 31 & 45 & 10 & 2 & \\
\hline Suntrust banks & 177 & 15 & 10 & 9 & 24 & 44 & 17 & 7 & 30 & \\
\hline Regions Financial & 127 & 16 & 11 & 27 & 19 & 35 & 12 & 16 & 24 & \\
\hline Fifth Third Banc & 117 & 17 & 15 & 44 & 45 & 41 & 35 & 46 & 46 & \\
\hline Northern Trust & 100 & 18 & 17 & 32 & 25 & 34 & 36 & 42 & 26 & \\
\hline Schwab (Charles) Corp & 109 & 19 & 27 & 15 & 31 & 43 & 43 & 18 & 36 & \\
\hline Keycorp & 89 & 20 & 16 & 46 & 46 & 38 & 31 & 40 & 45 & \\
\hline E Trade Financial Corp & 48 & 23 & 19 & 40 & 14 & 10 & 15 & 34 & 13 & \\
\hline Hudson City Bncp & 45 & 24 & 24 & 14 & 15 & 15 & 23 & 17 & 16 & \\
\hline
\end{tabular}


Panel A continued

\begin{tabular}{|c|c|c|c|c|c|c|c|c|c|c|}
\hline Popular Inc & 37 & 27 & 20 & 43 & 11 & 14 & 9 & 27 & 7 & \\
\hline Jefferies Group Llc & 35 & 28 & 22 & 6 & 9 & 5 & 10 & 6 & 3 & \\
\hline First Citizens-A & 21 & 31 & 32 & 45 & 22 & 11 & 24 & 32 & 19 & \\
\hline First Bancorp & 13 & 39 & 38 & 53 & 55 & 7 & 22 & 52 & 55 & \\
\hline Firstmerit Corp & 14 & 40 & 45 & 13 & 28 & 18 & 38 & 14 & 21 & \\
\hline Valley Natl Banc & 14 & 41 & 46 & 5 & 50 & 17 & 46 & 11 & 50 & \\
\hline Flagstar Bancorp & 14 & 42 & 30 & 47 & 13 & 16 & 7 & 45 & 4 & \\
\hline Citizens Republic & 9 & 46 & 41 & 51 & 54 & 13 & 18 & 50 & 54 & \\
\hline Impac Mortgage Holdings & 6 & 51 & 42 & 55 & 10 & 3 & 3 & 54 & 1 & \\
\hline Panel B: Europe & \multicolumn{9}{|c|}{2011 Systemic Risk Rankings } & \multirow[b]{2}{*}{ FSB } \\
\hline Bank & Asset value & rSYR & SRISK & $\Delta \mathrm{CoVaR}$ & $\mathrm{ES}$ & sSYR & sSRISK & $\mathrm{s} \Delta \mathrm{CoVaR}$ & sES & \\
\hline Deutsche Bank-RG & 2,164 & 1 & 1 & 9 & 2 & 6 & 4 & 13 & 6 & $\mathrm{Y}$ \\
\hline BNP Paribas & 1,965 & 2 & 2 & 4 & 10 & 25 & 16 & 8 & 19 & $\mathrm{Y}$ \\
\hline $\mathrm{HSBC}$ & 1,975 & 3 & 6 & 22 & 6 & 33 & 40 & 26 & 15 & $\mathrm{Y}$ \\
\hline Barclays Plc & 1,868 & 4 & 4 & 24 & 3 & 14 & 17 & 24 & 4 & $\mathrm{Y}$ \\
\hline RBS & 1,801 & 5 & 3 & 18 & 4 & 7 & 5 & 19 & 5 & $\mathrm{Y}$ \\
\hline ING Group & 1,274 & 6 & 5 & 8 & 11 & 16 & 10 & 10 & 21 & $\mathrm{Y}$ \\
\hline Banco Santander & 1,252 & 7 & 10 & 28 & 24 & 30 & 36 & 27 & 37 & $\mathrm{Y}$ \\
\hline Societe Generale & 1,181 & 8 & 7 & 11 & 9 & 8 & 6 & 22 & 14 & $\mathrm{Y}$ \\
\hline UBS & 1,167 & 9 & 9 & 27 & 7 & 13 & 25 & 28 & 9 & $\mathrm{Y}$ \\
\hline Lloyds Banking & 1,160 & 10 & 8 & 13 & 1 & 22 & 14 & 21 & 1 & $\mathrm{Y}$ \\
\hline Unicredit Spa & 927 & 11 & 11 & 12 & 18 & 12 & 13 & 15 & 25 & $\mathrm{Y}$ \\
\hline Credit Suiss-Reg & 863 & 12 & 12 & 15 & 8 & 17 & 23 & 17 & 8 & \\
\hline Commerzbank & 662 & 13 & 13 & 2 & 5 & 5 & 3 & 1 & 2 & $\mathrm{Y}$ \\
\hline Nordea & 716 & 14 & 14 & 20 & 21 & 35 & 28 & 14 & 26 & $\mathrm{Y}$ \\
\hline Intesa Sanpaolo & 639 & 15 & 15 & 10 & 22 & 31 & 21 & 9 & 27 & \\
\hline BBVA & 598 & 16 & 18 & 30 & 38 & 36 & 39 & 30 & 42 & \\
\hline Natixis & 508 & 17 & 16 & 16 & 17 & 19 & 15 & 20 & 16 & \\
\hline Dexia SA & 413 & 18 & 17 & 6 & 44 & 3 & 2 & 4 & 44 & $\mathrm{Y}$ \\
\hline Standard Chartered & 458 & 19 & 26 & 33 & 20 & 39 & 41 & 35 & 18 & \\
\hline
\end{tabular}


Panel B continued

\begin{tabular}{|c|c|c|c|c|c|c|c|c|c|}
\hline KBC Group & 285 & 20 & 19 & 7 & 16 & 24 & 7 & 5 & 13 \\
\hline Piraeus Bank SA & 233 & 23 & 21 & 39 & 25 & 11 & 24 & 40 & 29 \\
\hline Deutsche Boerse AG & 218 & 24 & 24 & 38 & 12 & 2 & 30 & 38 & 7 \\
\hline Natl Bank of Greece & 131 & 28 & 30 & 44 & 28 & 18 & 35 & 44 & 33 \\
\hline Banco Com Port-R & 107 & 30 & 28 & 40 & 33 & 4 & 9 & 36 & 35 \\
\hline Banco BPI SA & 93 & 32 & 31 & 26 & 39 & 9 & 12 & 23 & 38 \\
\hline CIC & 59 & 35 & 36 & 36 & 29 & 15 & 31 & 37 & 28 \\
\hline Bankinter & 49 & 36 & 34 & 35 & 34 & 1 & 1 & 34 & 30 \\
\hline Landesbank Berli & 43 & 38 & 37 & 17 & 36 & 10 & 8 & 11 & 31 \\
\hline Credito Emiliano Spa & 31 & 40 & 39 & 34 & 31 & 20 & 26 & 33 & 22 \\
\hline
\end{tabular}




\section{Appendix 4. Relationship between bailouts and orthogonalised banks' non-standardised systemic risk}

This Table reports Probit regressions where the dependent variable equals 1 if a bank was bailed out during the crisis. Size, expressed as log of total assets, and four orthogonalised non-standardised systemic risk measures (SRM), all computed in 2007Q2, are used as predictors. ES is logtransformed by $\ln (E S+1)$. Orthogonalised systemic risk is measured as the component of systemic risk that is orthogonal to Size. Panel A (B) shows results for the US (Europe). Detailed definitions of the systemic risk measures are shown in Appendix $2 . * * *, * *$ and $*$ denote significance at the 1\%,5\% and 10\% level. t-values have been computed with White (heteroscedasticity) standard errors. For specifications with significant systemic risk measure, the percentage of correctly classified banks is also reported, with the cup-off point being the ratio between the number of distressed banks and the total number of observations.

\begin{tabular}{|c|c|c|c|c|}
\hline \multicolumn{5}{|l|}{ Panel A: US banks } \\
\hline & rSYR & SRISK & $\Delta \mathrm{CoVaR}$ & ES \\
\hline Non-standardised SRM & $0.33 * *$ & 0.01 & -1.58 & 0.07 \\
\hline Size & $0.70 * * *$ & $0.64 * * *$ & $0.67 * * *$ & $0.65^{* * *}$ \\
\hline Pseudo $\mathrm{R}^{2}$ & 0.419 & 0.377 & 0.404 & 0.383 \\
\hline No of Obs. & \multicolumn{4}{|c|}{78} \\
\hline \multicolumn{5}{|l|}{ Panel B: European banks } \\
\hline & rSYR & SRISK & $\Delta \mathrm{CoVaR}$ & ES \\
\hline Non-standardised SRM & 0.08 & -0.04 & -0.10 & $-0.14^{*}$ \\
\hline Size & $0.51 * * *$ & $0.52 * * *$ & $0.52^{* * *}$ & $0.57 * * *$ \\
\hline Pseudo $\mathrm{R}^{2}$ & 0.209 & 0.206 & 0.206 & 0.267 \\
\hline No of Obs. & \multicolumn{4}{|c|}{54} \\
\hline
\end{tabular}

